This is a Working Copy Version (for personal use) of the paper, which has been published in Energy Conversion and Managenment. Citation:

F.P. Brito, N. Pacheco, R. Vieira, J. Martins, L. Martins, J. Teixeira, L.M. Goncalves, J. Oliveira, M. Hall, Efficiency Improvement of Vehicles using Temperature Controlled Exhaust Thermoelectric Generators, ENERGY CONVERSION AND MANAGEMENT, 203 (2020) 112255, https://doi.org/10.1016/j.enconman.2019.112255. Official copy available here:

\title{
Efficiency Improvement of Vehicles using Temperature Controlled Exhaust Thermoelectric Generators
}

\author{
F.P. Brito ${ }^{a}$, N. Pacheco ${ }^{b}$, R. Vieira ${ }^{c}$, J. Martins ${ }^{d}$, L. Martins ${ }^{c}$, J. Teixeira, L.M. Goncalves ${ }^{g}$, \\ J. Oliveira ${ }^{h}$,M. Hall ${ }^{i}$ \\ ${ }^{a}$ University of Minho, MEtRICs, DEM, Campus Azurem, 4800-058 Guimarães, Portugal, francisco@dem.uminho.pt \\ ${ }^{b}$ University of Minho, MEtRICs, DEM, Campus Azurem, 4800-058 Guimarães, Portugal, b7371@ dem.uminho.pt \\ ${ }^{c}$ University of Minho, MEtRICs, DEM, Campus Azurem, 4800-058 Guimarães, Portugal, b8024@ dem.uminho.pt \\ ${ }^{d}$ University of Minho, MEtRICs, DEM, Campus Azurem, 4800-058 Guimarães, Portugal, jmartins@dem.uminho.pt \\ ${ }^{e}$ University of Minho, MEtRICs, DEM, Campus Azurem, 4800-058 Guimarães, Portugal, lmartins@dem.uminho.pt \\ ${ }^{f}$ University of Minho, MEtRICs, DEM, Campus Azurem, 4800-058 Guimarães, Portugal, jt@dem.uminho.pt \\ ${ }^{8}$ University of Minho, CMEMS, DEI, Campus Azurem, 4800-058 Guimarães, Portugal, lgonvalves@dei.uminho.pt \\ ${ }^{h}$ BOSCH Portugal, Apartado 2458, 4701-970 Braga, Portugal, joao.oliveira7@pt.bosch.com \\ ${ }^{i}$ University of Texas at Austin, Mech. Eng. Dept, Austin, TX 78712, USA, mjhall@mail.utexas.edu
}

\section{Abstract:}

One of the main obstacles for the use of thermoelectric generators (TEGs) in vehicles is the highly variable thermal loads typical of driving cycles. Under these conditions it will be virtually impossible for a conventional heat exchanger to avoid both thermal dilution under low thermal loads and TEG overheating under high thermal loads. The authors have been exploring an original heat exchanger concept able to address the aforementioned problems. It uses a variable conductance thermosiphon-based phase-change buffer between the heat source and the TEGs so that a nearly constant, optimized temperature is obtained regardless of operating conditions. To the best of the authors' knowledge, the thermal control feature of the system is unique among existing TEG concepts. The novelty of the present work is the actual computation of operating pressure and temperature and the corresponding vaporization and condensation rates inside the thermosiphon system during driving cycles along with the assessment of the influence of the volumes and pre-charge pressure on electrical output. The global energy and emission savings were also computed for a typical yearly driving profile. It was observed that indeed the concept has unparalleled potential for improving the efficiency of vehicles using TEGs, with around $6 \%$ fuel and $\mathrm{CO}_{2}$ emissions savings using the system. This seems a breakthrough for such light duty applications since the efficiency of conventional (passive) systems is strongly deprecated by thermal dilution under low thermal loads and the need to by-pass high thermal load events to avoid overheating. On the contrary, the present concept allows the control of the hot face temperature of the TEGs even under highly variable thermal load (i.e. driving cycle) environments.

\section{Keywords:}

Energy efficiency, Exhaust heat recovery, Temperature control, Thermoelectric Generator, Thermosiphons

\section{Introduction}

The quest for reducing energy consumption, pollutants and greenhouse-gas (GHG) emissions is one of the main factors affecting the automotive industry research nowadays [1-3]. In terms of fuel consumption, the 2020 European Union target equates to approximately $4.1 \mathrm{~L} / 100 \mathrm{~km}$ of petrol or $3.6 \mathrm{~L} / 100 \mathrm{~km}$ of diesel. These targets will likely be even more restrictive for 2025 [4].

The internal combustion engine (ICE) dominance is being challenged by emerging technologies with long-term sustainability potential [1,5]. Moreover, there is a push from several EU countries to ban fossil fuel vehicles in the midterm, especially Diesels [6]. But it would be naïve to dismiss the current importance of research of ICE-based vehicles, as it enables a smooth, non-disruptive transition towards sustainable transportation [7]. A substantial improvement in overall vehicle efficiency has been achieved by the automotive industry over the years, not only through the internal combustion engine (ICE) improvement, e.g., by the enhancement of fuel-air mixing, introduction of turbocharging, variable valve timing systems, overexpansion [8-10] but also by the introduction of 
innovative solutions that improve the global energetic efficiency of the vehicle. Vehicle full electrification [11] or hybridization through the use of efficiency-oriented range extenders [12] and kinetic energy recovering systems [13], are some examples of the strategies adopted for that purpose, but other ways, such as waste heat recovery systems which produce electricity on-board, are also becoming attractive given the increasing degree of electrification of vehicles [2,14].

\subsection{Waste heat recovery systems}

In fact, the most abundant source of waste heat energy in ICEs is the one contained in the exhaust gases, whose temperature can sometimes surpass $700^{\circ} \mathrm{C}$. That energy amount is of the same order of magnitude as the mechanical energy provided to the driveshaft [2,3]. Additionally, due to its high temperature, it displays a good recovery potential from a second law of thermodynamics standpoint $[8,9,13,14]$.

One of the prominent waste heat recovery applications for the exhaust flow is the use of thermodynamic cycles such as the Organic Rankine Cycle (ORC) [15]. These systems may surpass efficiencies around $15 \%$ in automotive environment, although being mechanically complex [16] .

Another attractive solution to harvest the energy released by exhaust gases consists on transforming it directly into electrical power avoiding moving parts and the corresponding maintenance costs. This is possible when using thermoelectric generators (TEGs), which produce electricity when there is a temperature difference across the module faces because of the Seebeck effect $[2,3,17,18]$. The exhaust gases heat the hot face and a cooling circuit keeps the opposite face (cold face) at as low a temperature as possible. Efficiencies of commercially available TEG modules are around 5\% for the automotive temperature range [15], typically lower than those of ORC systems, although a lot of work has been developed recently in nanostructured materials and the exploring phenomena such as quantum confinement, which may increase the efficiency to values closer to ORC [2,17]. Due to their simplicity, lack of maintenance and scalability, several vehicle manufacturers have been exploring the potential of these systems for achieving fuel efficiency improvements above 10\% [3,19-22].

\subsection{Energy Savings}

In conventional vehicles a significant amount of mechanical power must be diverted from the engine to auxiliary components such as pumps, AC compressor and the alternator [9]. If the electrical energy normally provided by the alternator could be instead provided by waste energy recovery systems, then the fuel consumption and GHG emissions would be significantly reduced.

In the extensive monitoring program of light duty vehicles made by the Idaho National Laboratory [23], the electric power consumption of the auxiliary loads was measured for four different vehicles. Benchmark testing was done for standard driving cycles on a dynamometer. These vehicles were also tested on the road for a 12 month period. The average measured power supplied by the alternator was around $500 \mathrm{~W}$.

Additionally, if mechanically-driven auxiliaries such as AC compressors, water and oil pumps were also substituted by electric driven ones and all auxiliaries then powered by energy recovery systems such as TEGs and regenerative braking, then the fuel savings could be even greater. Some references can be found relating typical net power, consumption and/or efficiency of these auxiliaries [24-28]. It already highlights the advantages of using electrically-driven auxiliaries given their typically higher efficiency and flexibility of operation. Thus, waste energy recovery technologies could power these components eliminating their engine mechanical load, with these savings being multiplied since a given mechanical saving corresponds to an even higher fuel saving through the component/engine efficiency chain.

Table 1 summarizes the net power, efficiency and consumed mechanical power of several auxiliaries obtained from literature for the average engine speeds of the driving cycles tested in the present work ( 2000rpm / 3000rpm for the WLTP Class 3 / Custom Highway driving cycles, respectively). 
Table 1 -Estimated net power, efficiency and engine mechanical power consumed by auxiliary

components present in a light vehicle

\begin{tabular}{lllll}
\hline Component & $\begin{array}{l}\text { Net Power @ 2k/3k } \\
\text { rpm [W] }\end{array}$ & $\begin{array}{l}\text { Avg Efficiency @ } \\
\text { 2k/3k rpm [\%] }\end{array}$ & $\begin{array}{l}\text { Mech Power @ 2k/3k } \\
\text { rpm [W] }\end{array}$ & Ref. \\
\hline Alternator & $\sim 500[23]$ & $55 / 50$ & $909 / 1000$ & {$[25,27]$} \\
\hline Water pump & $185 / 186$ & $38 / 48$ & $493 / 388$ & {$[26]$} \\
\hline Air conditioning & - & - & 475 & {$[24]$} \\
\hline Oil pump & $74 / 138$ & $40 / 37$ & $186 / 373$ & {$[28]$} \\
\hline
\end{tabular}

\subsection{Temperature controlled TEG generator}

103

There are some challenges typical of TEG systems. On one hand, their output is very sensible to the thermal level as it is proportional to the square of the temperature difference across the thermoelectric elements. Therefore, the performance will be highly impacted if the temperature at the hot face of the TEG modules is not close to the modules' limit temperature [18]. On the other hand, if the heat exchangers are designed to maximize heat absorption, the risk of overheating becomes real for the case of exhaust heat recovery applications, as commercially available TEGs are temperature limited. For that reason, the TEG systems normally found in literature are designed for a limited range of exhaust powers and then incorporate by-pass valves to divert part or all the exhaust flux from the heat exchanger during high thermal load events to avoid system meltdown [19-22]. Unfortunately, the total available exhaust energy in typical urban driving is limited. The fact that most existing systems waste a substantial portion of this energy might ultimately justify their poor performance [29]. That is why a concept that would be able to somehow control the thermal level at which the exhaust heat would be delivered to the TEG modules could provide breakthrough performance for automotive TEGs and possibly render them viable for real world applications.

One way of controlling the temperature of a heat absorption process is to use phase change. These phenomena occur at very specific temperature ranges which depend solely on pressure [30]. Heat Pipes (HPs) and Thermosiphons (TSs) are devices which operate based on phase change, and several works involving these devices in conjunction with TEGs have been performed [31]. TSs and HPs may indeed improve the heat transfer both at the heat source and at the heat sink of TEG modules since the thermal resistance of phase change processes is generally quite low [32]. However, the control over the temperature of the heat transfer process using these devices requires that HPs and TSs also contain a non-condensable gas inside them. The saturation (boiling) temperature of the phase change fluid will be a function of the pressure of this gas.

Previous papers from the authors have shown some quite original concepts developed using these variable conductance thermo-siphon (TS) devices. Through the application of these it was possible, not only to keep the thermal resistance of the system to a minimum [29], but also to passively control the operating temperature of TEGs, avoiding both thermal dilution and overheating [33-35]. This is quite a unique feature among TEGs and the present paper is a continuation of these works.

So, variable conductance TS (VCTS) are heat transfer devices with a high heat transfer rate due to their fundamental principle of phase changing (Fig. 1). The variable conductance designation refers to the ability of the TS to vary the active heat transfer area of the heat sink (condenser) depending on the heat rate absorbed at the heat source (evaporator). This is only possible due to the presence of the non-condensable gas in addition to the phase change fluid. The VCTS consists of a closed chamber/pipe containing a phase change liquid at the bottom (evaporator) and a pressurized noncondensable gas filling the rest of the volume. The evaporator is linked to a condenser to where the TEG modules are attached (Fig. 1). As the TS starts absorbing heat from the exhaust, the water will 
heat up and eventually boil, generating vapour. As further heat is supplied to the system, the vapour will gradually fill more and more volume of the TS, and the non-condensable gas will be compressed by the vapour and reduce its volume. Interestingly, there is a stratification of both the condensable and non-condensable gases observed experimentally $[33,34]$ and the heat transfer will occur mainly along the vapour region (Fig. 1), with the non-condensable gas region being able to be treated, in practical terms, approximately adiabatically. The area of the condenser occupied by vapour will be proportional to the thermal load. The heat will therefore be transmitted to the modules by the condensation of the vapour. These condensates will then fall back to the evaporator, restarting the process. When there is a decrease in the exhaust thermal load, the rate of vapour condensation will exceed the rate of vaporization such that the area of the condenser condensing the vapour will decrease. This happens when there is a drop on the exhaust thermal load [33-35].

Associated with the variable active area characteristic of the system is the ability to process the heat transfer at a controlled temperature irrespective of thermal load. In fact, the heat will always be transferred to the modules at the boiling temperature of the working fluid. This temperature will depend solely on the internal pressure of the system. Therefore, if the internal pressure can be controlled within certain limits, so will the temperature [33-35]. Basically, the pressure will be a function of the total volume of the system and of the masses and densities of the fluids present inside the TS. The higher the volume, the less the pressure will vary between idle and full load.

Initial models by the authors have considered that volume was sufficiently high so as to consider the pressure as constant, and indeed this was confirmed experimentally [33-35]. Unfortunately, large volumes are not practical for implementation in a vehicle, so it would be important that the modelling would allow to compute the variation of pressure during system operation and for a finite system volume.

The concept of Fig. 1a can be implemented as a generator like the one presented in Fig. 1b, which is the geometry simulated in the present research and which resembles the proof-of-concept lab prototype being tested by the authors. It has a separated evaporator and condenser and it includes a buffer, which is an additional volume located at the top of the condenser that can accommodate excess vapour production in high thermal load events, when the condenser exceeds its maximum capacity. It then supplies this excess when the thermal load falls. This way, the condenser will remain fully active for a longer time.

If there is more vapour than the condenser can handle and the buffer can store, the excess vapour will be condensed in a secondary heat exchanger ("Excess Power Condenser") thus preventing further pressure rise. It is necessary to assess the influence of these elements in the overall performance of the device. A prototype which conveniently implements this concept in a real vehicle is still being developed, but of course the evaporator will be located along the exhaust pipe after the catalyst, while the location of the condenser will be more flexible, as it may be installed anywhere near it, as long as it is above it and it is at least slightly inclined to allow for gravity assist. The condenser may be more compact by having more modules and TS stacked in parallel. The connection to the vehicle power electronics system of the auxiliaries/battery will be done as usual, through Maximum Power Point Tracking electronics feeding the system, probably with several converters for the various voltage levels. This concept will be most suitable in a heavy duty vehicle, where spatial constraints are less of an issue. Nevertheless, the current work has focused on a light duty vehicle application. This was done not only because it is the biggest market segment but also because it is an especially challenging application in terms of available thermal power and variability, a situation where the developed model will be most useful. 


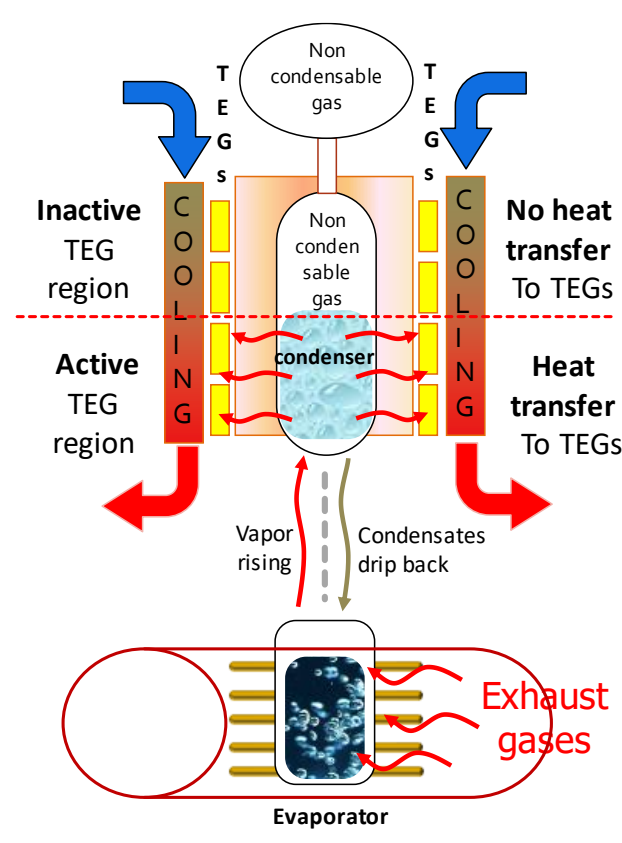

(a)

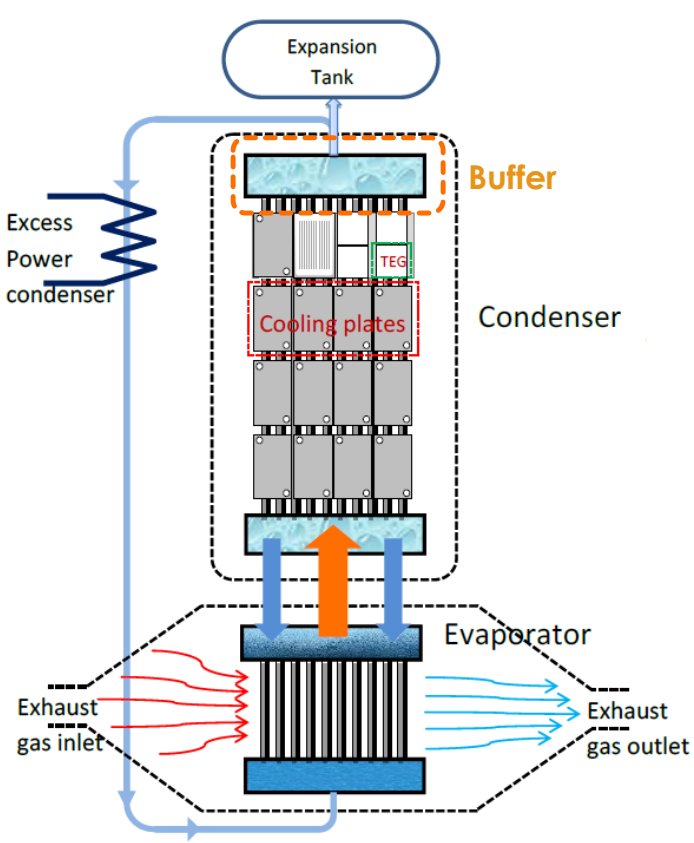

(b)

Fig. 1 - (a) Outline of the operation of a Variable Conductance Thermosiphon heat exchanger with exhaust gases as heat source and thermoelectric modules as heat sink, (b) Exhaust heat exchanger based on the same concept.

The present publication details for the first time the algorithm developed for calculating the dynamic variation of the internal pressure and temperature during highly variable driving cycles (the rest of the model was already detailed in previous publications $[34,35]$ ). The influence of system volume and system pre-charge pressure on system performance is assessed. Finally, a system with a roughly optimized configuration is assessed for typical European driving profiles, calculating the energy and $\mathrm{CO}_{2}$ emissions savings obtained with the system. Also the maximum potential savings are estimated for the cases where waste energy recovery systems would enable one to eliminate the alternator or even allow for the substitution of the AC compressor, the water and oil pumps by electrically driven components and fed by the electricity generated by these systems.

\section{Modelling}

\subsection{Global approach}

The ultimate goal of the model developed is to calculate the output electric power of the TEGs along a driving cycle. The model predicts the instantaneous exhaust load, the total thermal power absorbed by the system, the heat crossing the modules, the heat sources and sinks therein and the resulting temperature differential across the TE pellets which determines the voltage generated by the system. To obtain these predictions, conduction, convection, boiling and thermoelectric effects are modelled accordingly, using either numerical finite difference schemes or empirical correlations.

The vehicle and engine models predict the required instantaneous engine map position (torque, speed) to fulfil the driving cycle and the corresponding exhaust flow rate and inlet temperature for each time step [37]. The engine model is based on steady-state engine maps [10,36]. These models have already been described elsewhere [35], and included validation with a small prototype [34].

The thermosiphon (TS) model governs the heat transfer along the whole system, from the absorption of the heat at the exhaust flow to the rejection of heat absorbed at the cold face of the modules to the water cooling flow. The present article details only the algorithm for computing the masses, volumes and pressures of the liquid, vapour and non-condensable gas inside the system. This is an update of 
the model for constant pressure, already presented before [34,35], only briefly described here. The solution algorithm is outlined in Fig. 2.

Exhaust gases thermal input

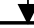

Convection at exhaust, conduction across TS, nat. convection/boiling in the evaporator.

Calculate air, water, vapour masses and volumes and resulting active condenser length.

\section{$\checkmark$}

Heat transfer at condenser/module/cooling section Electric power production at modules.

$\checkmark$

Re-calculate air, water, vapour masses and volumes due to condensation.

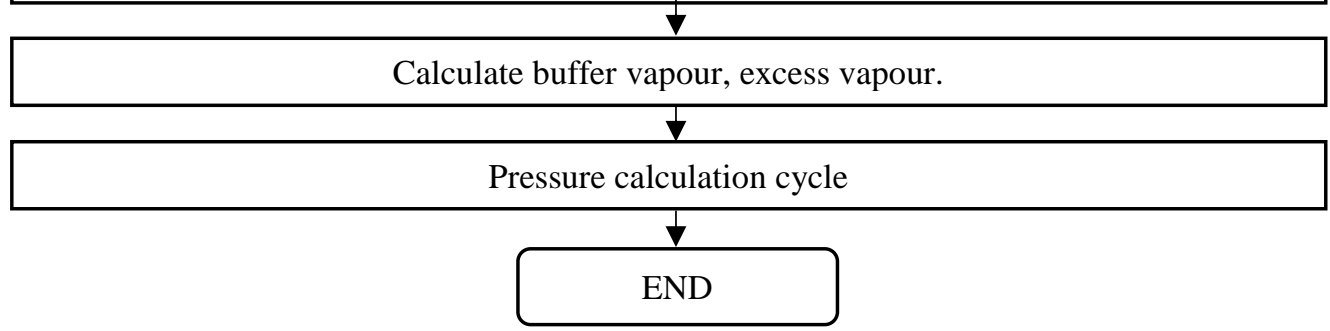

Fig. 2 - Scheme of the thermosiphon model

Basically, the TS model incorporates the following sub-models, which are only separated conceptually, as they depend on and interact with each other:

- Exhaust heat exchanger/Evaporator: this sub-model receives as an input the exhaust gas temperature and flow rate and then computes the heat absorbed by the system, the temperature levels and the boiling rates on the inside of the TS if saturation conditions have been met. It will depend on the convection at the finned outer surface of the TS in contact with the gases, on the conduction through the walls of the TS and finally on the natural convection/nucleate boiling on the inside. These calculations are performed using a unsteady 1D heat transfer finite difference scheme which has already been presented in previous publications and uses relevant forced convection, natural convection and nucleate boiling empirical correlations [34,35]. The boiler used in these simulations is a staggered pipe HE as described in [35], but the concept may also be implemented with a compact boiler similar to an Exhaust Gas Recirculation (EGR) cooler.

- Condenser/TEGs/Cooling: This sub-model computes the heat transfer between the active TS condenser region (fourteen $10 \mathrm{~mm}$ pipes), the TEG modules and the cooling system (finned water cooling plates). Again, most of this modelling has been presented before [34,35]. It accounts for the heat transfer by film condensation at the area of the condenser which is occupied by vapour (also called the active condenser region), the heat transfer by conduction through the inner condenser walls, the modules attached to the outer condenser walls and the convection at the cooling plates. The heat transfer scheme used is a 1D quasi-steady state scheme accounting for localized and distributed heat sources and sinks due to Joule and Peltier effects. The electric power generated due to the Seebeck effect is a consequence of the temperature levels obtained in these calculations. The electric current obtained in these computations will also affect the thermal calculations through the Joule and Peltier effects.

- Interaction model: This sub-model will combine the results from the Exhaust heat exchanger / Evaporator sub-model and the Condenser/TEGs/Cooling model. It computes the volumes occupied by each fluid (liquid water, vapour and non-condensable gas) in the system. It will also compute the active region of the condenser, that is, the region of the condenser occupied by vapour and not by 
non-condensable gas. The computation of pressure, which is a novelty of the present analysis, is also computed at the end of these calculations.

Some assumptions made are worth noting: The non-condensable gas (air) is considered as an ideal gas, while the phase-change fluid (water) displays compressed liquid or saturated vapour properties according to its liquid or vapour phase. Pressure variations along the TS have been neglected with vapour having been considered as isothermal. A perfect stratification of vapour and non-condensable gas has been considered, based on literature and previous experimental evidence, with the noncondensable gas being treated as adiabatic. Given complete stratification, the impact of the noncondensable gas on the heat transfer coefficient at the vapour region has been neglected. An equilibrium pressure and the active region (the region occupied by vapour) was calculated for each time step based on mass and volume computations for all fluids (liquid, vapour, non-condensable gas). Boiling and condensing rates were derived from the calculated heat fluxes at the walls and from the latent heat of liquid/vapour phases change. Average thermoelectric properties have been evaluated for the average temperature of the TE elements.

\subsection{Interaction model description}

The calculation of the energy absorbed by the system, $E_{\text {wall in }}$, for time step $\Delta t$, is an integral part of the heat transfer model of the exhaust heat exchanger [35]. This energy may be positive (the working fluid is being heated by the exhaust flow) or negative (exhaust is cooler than water and cooling it). Also, the liquid water may be instantaneously below, under or above saturation conditions. So, there are several possible physical scenarios that can occur, as outlined in Table 2.

271 Table 2 - Possible heat transfer scenarios for the evaporator

\begin{tabular}{|c|c|c|c|c|c|}
\hline Scenario I & Scenario II & Scenario III & Scenario IV & Scenario V & Scenario VI \\
\hline \multirow{4}{*}{$\begin{array}{l}\boldsymbol{E}_{\text {wall in }}>\mathbf{0} \\
\boldsymbol{T}_{\boldsymbol{T S}}<\boldsymbol{T}_{\text {boil }} \\
\boldsymbol{E}_{\text {wall in }} \\
<\boldsymbol{E}_{\text {to boiling }} \\
\text { Water/HE } \\
\text { body heating, } \\
\text { no vapour } \\
\text { production }\end{array}$} & $E_{\text {wall in }}>0$ & $E_{\text {wall in }}>0$ & $E_{\text {wall in }}<0$ & $E_{\text {wall in }}<0$ & $E_{\text {wall in }}<0$ \\
\hline & $T_{T S}<T_{\text {boil }}$ & $T_{T S}=T_{\text {boil }}$ & $T_{T S} \leq T_{\text {boil }}$ & $T_{T S}>T_{\text {boil }}$ & $T_{T S}>T_{\text {boil }}$ \\
\hline & $\begin{array}{l}E_{\text {wall in }} \\
>E_{\text {to boiling }}\end{array}$ & & \multirow{2}{*}{$\begin{array}{l}\text { Water/HE } \\
\text { body cooling }\end{array}$} & & \\
\hline & $\begin{array}{l}\text { Water/HE } \\
\text { body heating }\end{array}$ & $\begin{array}{l}\text { Vapour } \\
\text { production only }\end{array}$ & & $\begin{array}{l}\text { Water/HE body } \\
\text { cooling: }\end{array}$ & $\begin{array}{l}\text { Water/HE body cooling } \\
\text { and vapour production }\end{array}$ \\
\hline \multirow{3}{*}{$\begin{array}{l}\text { Saturation } \\
\text { conditions are } \\
\text { not achieved }\end{array}$} & $\begin{array}{l}\text { followed by } \\
\text { vapour } \\
\text { production }\end{array}$ & $\begin{array}{l}\text { Water was } \\
\text { already at } \\
\text { saturation }\end{array}$ & $\begin{array}{l}\text { Water is } \\
\text { hotter than } \\
\text { HE (abrupt } \\
\text { thermal load }\end{array}$ & $\begin{array}{l}\text { Water is hotter } \\
\text { than HE and } \\
\text { above saturation }\end{array}$ & $\begin{array}{l}\text { Water is hotter than } \mathrm{HE} \\
\text { and above saturation } \\
\text { conditions. }\end{array}$ \\
\hline & \multirow{2}{*}{$\begin{array}{l}\text { saturation } \\
\text { conditions } \\
\left(T_{T S}=T_{b o i l}\right) \\
\text { achieved } \\
\text { during the } \\
\text { time step }\end{array}$} & conditions & & conditions. & Heat released to the $\mathrm{HE}$ \\
\hline & & & & $\begin{array}{l}\text { Heat released to } \\
\text { the HE is } \\
\text { sufficient to } \\
\text { leave saturated } \\
\text { conditions }\end{array}$ & $\begin{array}{l}\text { is not sufficient to } \\
\text { achieve non-saturated } \\
\text { conditions, so it releases } \\
\text { the rest as latent heat } \\
\text { until achieving saturation }\end{array}$ \\
\hline
\end{tabular}

Depending on the initial water temperature and on the amount of heat supplied during that time step, the water may only heat up (Scenario I), undergo a heating, up to the saturation conditions, followed by boiling with the remaining heat (Scenario II), or only boil (Scenario III). Other analogous scenarios are possible for the case where $E_{\text {wall in }}$ is negative (water is being cooled by the cooler exhaust stream due to a sudden drop in thermal load). This cooling may occur always below saturation conditions (Scenario IV) or above saturation conditions. For the latter case the cooling of the phase change fluid may be sufficient to achieve non-saturated conditions. If not the remaider of the heat will be released as latent heat until achieving saturation (Scenario VI). 
When the TS water temperature, $T_{T S}$, is lower than the boiling temperature, $T_{\text {boil }}$, the energy needed for the water and the metal parts to achieve boiling/saturation conditions, $E_{\text {to boiling, }}$ is calculated through (1).

$E_{\text {to boiling }}=\left(m_{\text {water }} c_{p_{\text {water }}}+m_{\text {metal }} c_{p_{\text {metal }}}\right)\left(T_{\text {boil }}^{p-1}-T_{T S}^{p-1}\right)$

The mass of metal, $m_{\text {metal }}$, with a given specific heat capacity, $c_{p_{\text {metal }}}$, is added to simulate the thermal inertia of the generator. The water/HE temperature variation due to sensible heat is calculated according to (2).

$T_{T S}^{p}=\frac{E_{\text {wall in }}}{m_{\text {water }} c_{p_{\text {water }}}+m_{\text {metal }} c_{p_{\text {metal }}}}+T_{T S}^{p-1}$,

When water is under saturation conditions $\left(T_{T S}=T_{\text {boil }}\right)$, the mass of generated vapour will be calculated by dividing the boiling energy $E_{v a p}$ by the latent heat of vaporization, $\Delta h_{L V}$. As for the total vapour and water masses, $m_{\text {vapour }}, m_{\text {water }}$, they need to be updated due to this generation of vapour.

When $E_{\text {wall in }}<0$ the heat transfer direction is reversed, that is, the water is releasing heat to the exhaust because it is hotter than it (low exhaust gas power, as when fuel injection is cut during vehicle decelerations). It may lose heat to the exhaust in the form of sensible heat according to (2) or also by latent heat. The temperature of the liquid water may be temporarily above saturation conditions (a non-equilibrium condition) and therefore there is excess energy (calculated similarly to (1)) that is released. If the excess energy is lower than $E_{\text {wall in }}$ (scenario V), then the water will release heat to the cooler TS walls according to (2) and its final status will be below saturation conditions with no vaporization occurring. Otherwise, (scenario VI), the remainder of the excess energy will be released to generate vapour. This can be seen as non-equilibrium superheated liquid water that instantly cools down to saturated conditions by generating vapour.

Regardless of the situation under effect, the volumes of vapour and water must be determined by dividing the corresponding masses by their densities. The air volume will be calculated by subtracting the total volume by the vapour and water volumes. Note that liquid water will also vary its density slightly depending on temperature.

\subsection{Condenser - TEGs}

Once the volumes of water and vapour become higher than the internal volumes of the evaporator and the flange (volume existing between the evaporator and the condenser) some vapour volume will start to be present inside the condenser and therefore heat will be released by the condensing vapour to the TEGs at the active condenser zone. The model for the condenser region and the TE modules was presented in earlier work [34,35]. It includes the thermoelectric effects such as diffuse and localized heat sources and sinks due to the Joule and Peltier effects. It is a quasi-steady-state model something justified by considering that the oscillations in thermal input will be damped by the thermal inertia of the evaporator. A 1D heat transfer model is used, but incorporating conduction shape factors to consider the 3D effects and accounting for the all thermal resistances including contact resistances in all interfaces [38]. The condenser model uses the temperature of the water vapour $\left(T_{\text {boil }}\right)$ and the active height of vapour in condenser $\left(L_{\text {vapour }}\right)$ as inputs, while the outputs are the condensation energy $\left(E_{\text {cond }}\right)$ and the TEGs electric power $\left(P_{e}\right)$. 
At the condenser wall interface the heat transfer is considered to occur due to film condensation. The amount of condensed matter is quantified by dividing $E_{\text {cond }}$ divided by $\Delta h_{L V}$. Subsequently, the vapour and water volumes, as well as the height of vapour in the condenser should be updated as explained above.

If the vapour region exceeds the condenser limits, it will fill the buffer/storage volume. If it also exceeds the buffer limits it will be totally condensed by the excess vapour condenser.

The non-condensable gas inside the system is compressed/expanded when vapour is produced/condensed, so it will affect the pressure. Under these circumstances, a new TS pressure $\left(\mathrm{p}_{H P}^{u}\right)$ and a new water boiling temperature $\left(T_{\text {boil }}^{u}\right)$ must be calculated. The pressure correction algorithm is iterative and done with the isothermal compression of a perfect gas. A relaxation factor is used to stabilize the results, avoiding pressure calculation instabilities.

The boiling water temperature will vary since it is a function of the TS pressure. The vapour density will also vary for each iteration with pressure and temperature. The cycle stops and the pressure is assumed converged once the absolute error is less than 0.01 bar. After the condenser algorithm is completed, the calculation begins for a new time step in the evaporator model.

\subsection{Consumption and savings}

In order to compute the energy consumption of the vehicle, a driving cycle energy model [37] in combination with an engine model [10] have been used. The engine model provided the brake torque and power, the exhaust power and exhaust temperature maps as a function of engine load and speed. The driving cycle energy model provided the instantaneous power required to fulfill a given driving cycle based on the vehicle characteristics and the several energy requirements due to acceleration, rolling resistance (including tyre slip and friction due to sinuosity) aerodynamic drag resistance. This allowed calculating the instantaneous fuel consumption of the vehicle. The fuel and $\mathrm{CO}_{2}$ emissions savings were estimated by first calculating the instantaneous electric power produced by the TEG and then calculating the corresponding saving in fuel due to the reduction in alternator load. The CO2 savings are directly obtained from the fuel savings since they are proportional. Two other savings calculations were made. One considering what would be the savings if the alternator could be eliminated altogether and electricity be supplied by the TEG and other energy recovery systems such as regenerative braking. The other considering not only that the alternator would be eliminated but also that a group of mechanical peripherals would be substituted by electric peripherals fed by energy recovery systems.

\section{Results and discussion}

As mentioned, in previous works the system was considered to have a sufficiently high volume so as to consider the variation of pressure as negligible [35]. This approach was successfully validated in those works, while the experimental observation of thermal control of thermoelectric generators using a variable conductance thermosiphon heat exchanger confirmed the viability of the present concept $[33,34]$. The main update of the model described in the present work is the ability to compute the evolution of pressure and corresponding boiling temperature inside the system instead of considering the constant pressure simplification. Therefore, the model was run for a set of conditions suitable to assess the influence of volume and initial and pressure on the performance of the system. The first results here presented assess the influence of both the volume of the expansion volume and of the buffer volume. These values were fixed in previous publications. The buffer corresponds to the extra volume that the vapour can occupy when the condenser is already full. Separating the buffer and the expansion volume is an excess vapour condenser, therefore, the expansion volume is a volume which has been added to the system downstream of the excess vapour condenser. So, the vapour will never reach it, only the non-condensable gas. Results were computed for two different driving cycles 
(standard WLTP class 3 and custom Highway cycle) and combinations thereof. The simulation conditions are the same used for the standard case in [35].

\subsection{Influence of expansion volume}

Fig. 3 highlights the evolution of pressure, module hot face temperature and electric power output along the custom Highway driving cycle, for several expansion volumes. As explained before, the expansion volume is the volume of the system located downstream of the excess vapour condenser. Because of this, no excess vapour can be accumulated in this volume. The higher this volume, the less will be the pressure variation of the system between low and high thermal loads.

It may be seen in Fig. 3 that the higher the expansion volume, the less will pressure vary along the cycle. The pressure increases due to the vaporization of water within the interior of the system. It starts decreasing once the vaporization rate is lower than the condensation rate. It may be seen that until around 200 seconds into the cycle the pressure does not vary significantly. This is because the system is still heating up and no vapour is produced (Scenario I). Once boiling conditions are met (Scenario III), the increase in vapour content will cause an increase in the pressure. Pressure variation will be stronger the smaller the total volume of the system, because the non-condensable gas will act as a kind of pneumatic spring. The initial pressure was set so that the maximum allowable thermoelectric module temperature $\left(250^{\circ} \mathrm{C}\right)$ would be achieved in all simulations. It is worth noting that the system achieves full operation in several portions of the cycle. One of such occasions can be observed by the plateau occurring around 500 seconds. This plateau happens because the system is full of vapour, having occupied not only the whole condenser area, but also the whole buffer area located after the condenser. When the excess vapour starts to condense (on a separate heat exchanger) the pressure can no longer increase. The temperature of the hot face of the active modules may be seen in Fig. 3 b). It depends on the inner thermosiphon temperature, which is the boiling temperature for the pressure in that moment. But it will be smaller than the thermosiphon temperature as it will be deprecated by the several thermal resistances between the vapour and the module, including the condensation resistance. The higher these resistances, the higher will be the temperature drop between the vapour and the module hot face.

A curious phenomenon may be observed in Fig. 3 b): for small expansion volumes, the maximum module temperature occurs for the highest thermal loads (for example, around 500 seconds), but the opposite occurs for high thermal loads (for example, at 1000 seconds). This may be explained by two phenomena. In the case of big expansion volume systems, the boiling temperature will vary very little between low and high thermal load. However, the thermal resistance due to film condensation will increase as the load of the condenser increases. This is a known issue in film condensation since longer condensation films produce thicker liquid layers, which hamper condensation heat transfer [30]. This causes the temperature of the active modules to be highest when the condenser load is lowest, and vice versa. When the expansion volume is small, the pressure variations will be stronger between low load and high load. Although the thermal resistance also increases, the boiling temperature will rise and therefore the highest module temperatures will be achieved for higher thermal loads. Fig. 3 c) presents the resulting electrical power output of the system along the HW driving cycle. This electric power depends not only on the active condenser area (the area of the condenser filled by vapour instead of the non-condensable gas) but also on the temperature achieved at the hot and cold faces of the active TEG modules. It may be seen in Fig. 3 c) that the system with the lowest volume is the first one to start producing electricity. This is so because smaller systems need to start with a lower pressure, thus a lower boiling point. This makes it easier for the system to achieve boiling conditions, starting earlier. Fig. 3 c) also shows that the lower volume system induces a higher power stability, a kind of damping in the electric power curve.

One would assume that bigger expansion volumes would allow a higher storage of excess vapour during high thermal load events. However, this is not the case. It may be seen in Fig. 3 c) that after the high load events end (for example, around 600 seconds) the fade in electric production is less 
pronounced in smaller expansion volume simulations than in bigger ones, indicating that smaller, not bigger expansion volumes allow for more excess vapour storage. The reason for this counter-intuitive effect can be explained as follows: since all vapour going beyond the buffer will be condensed at the excess vapour condenser, the added expansion volume will not contribute for vapour storage. In reality, it is the buffer volume (the volume that is located between the main condenser and the excess vapour condenser) which effectively allows for excess vapour storage, not the expansion volume. In this case, the buffer volume is kept constant at 0.51 . But this still does not explain why smaller expansion volumes seem to provide more storage than bigger ones. The reason for this can be seen in Fig. 3 a). Smaller expansion volumes induce a strong increase in pressure, (it can surpass 55 bar), whereas larger expansion volumes have fairly constant pressure values slightly above 40 bar. Stronger pressures mean much denser vapour, stored at a higher temperature. Therefore, it seems that for a given buffer volume, smaller expansion volumes will provide more mass of excess vapour storage than larger ones, and therefore, more energy. This induces higher average electric power output as seen in Fig. 4 a).

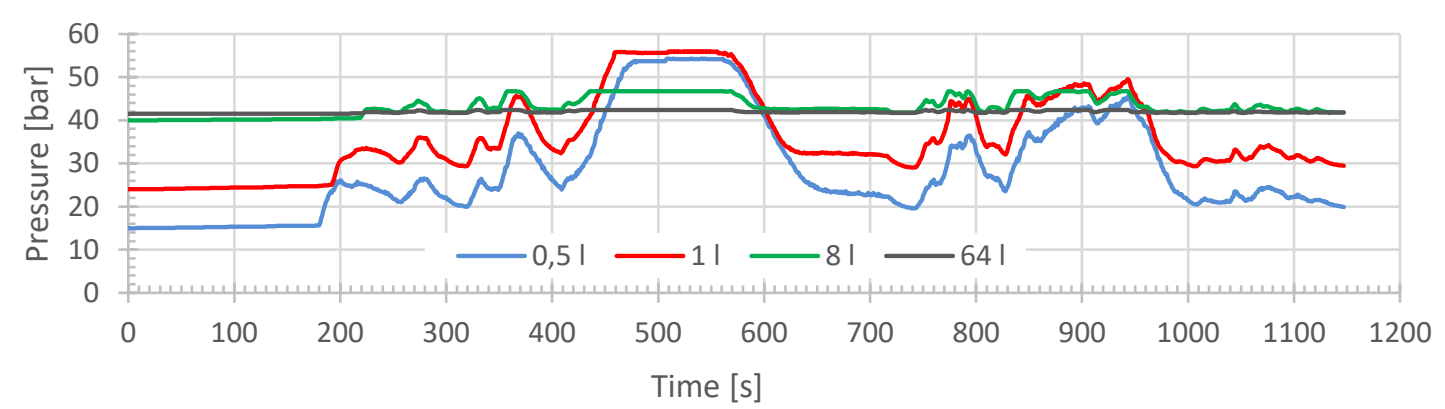

a)

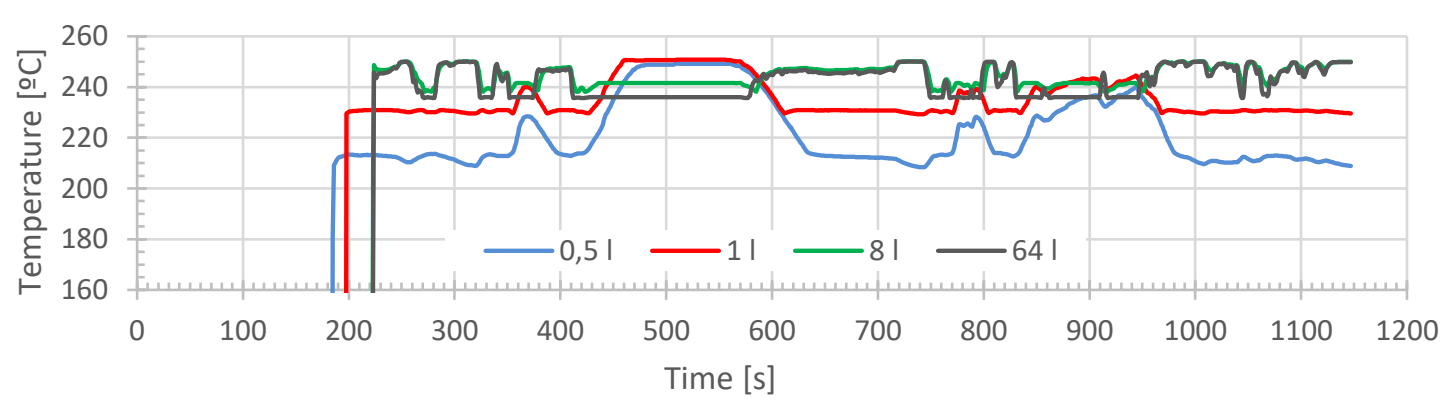

b)

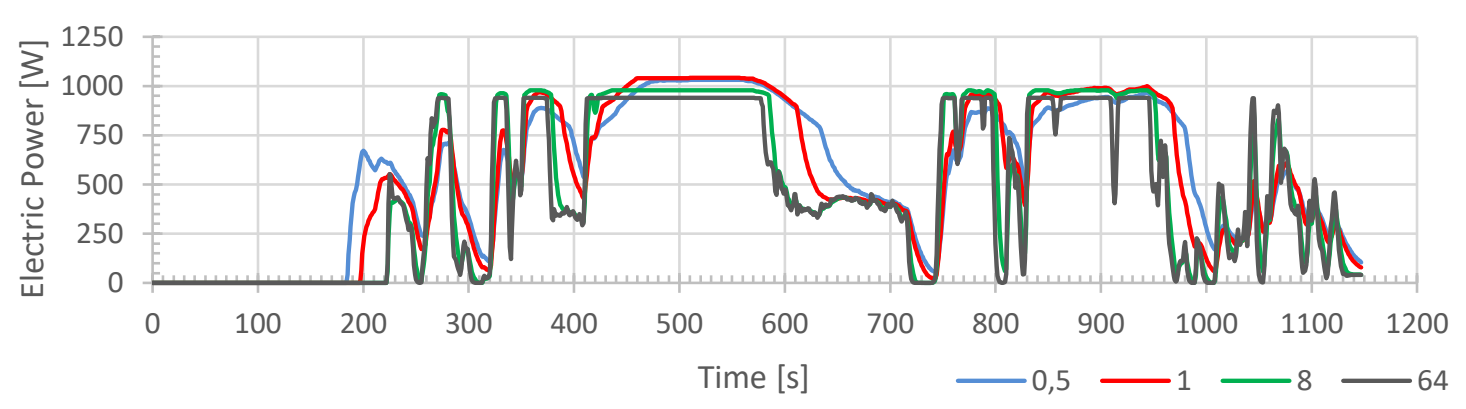

c)

Fig. 3 - Evolution of pressure (a), module hot face temperature (b) and electric power output (c) along the custom Highway driving cycle for several expansion volumes (buffer volume 0,5 l)

Given the much higher average load of the HW cycle, its average electric power output is nearly the double of that of the WLTP class 3 cycle. On the other hand, if the results are analysed in terms of 
average energy produced per unit distance, the results of the two cycles are much closer, as seen in Fig. 4 b). This means that the energetic performance of the system is similar for both cases and the system is able to efficiently absorb energy even with lower thermal load driving cycles as the WLTP cycle.

It may further be seen that the expansion volume has less of an effect over the power produced in the WLTP3 cycle than the HW cycle. This might be linked with the smaller range of exhaust powers encountered in the WLTP3 cycle which yields a smaller pressure variation even with small expansion volumes.

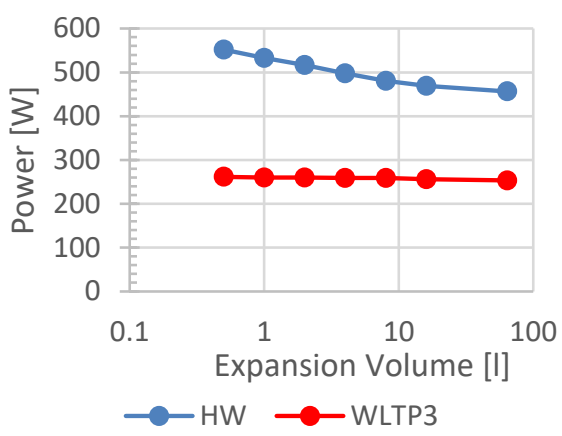

(a)

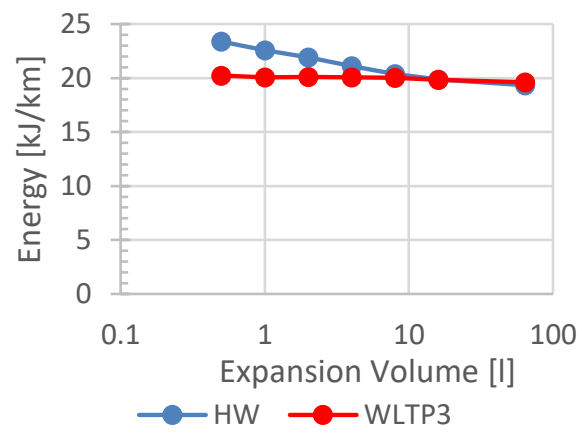

(b)

Fig. 4 - Influence of expansion volume on (a) average electric power output and (b) energy produced per $\mathrm{km}$ (buffer size $0.5 \mathrm{l}$ )

\subsection{Influence of buffer volume}

Fig. 5 shows the influence of different buffer volumes on the custom highway cycle for the pressure, temperature and electric power. As explained before, the buffer volume is the volume of the system located between the last row of modules and the excess vapour condenser. The higher this volume, the higher will be the accumulation of vapour under excess power events.

Once again, it may be seen that the higher the volume, the lower the range of pressure and temperature variation. At the same time, increasing the buffer size relatively to the expansion volume size increases the vapour accumulation capacity.

Fig. 6 shows the variation of the average electrical power output with the variation of the volume and buffer volume for both the HW and the WLTP3 cycle. It seems that for the high power HW cycle, larger buffer sizes tend to increase slightly the average output (around $40 \mathrm{~W}$ when increasing from a 0.51 buffer to one with 41 ). However, it seems preferable to use smaller buffer volumes because space is an issue and the difference between them reduces drastically for the smaller expansion volumes. Also, smaller buffers allow for a closer control over the maximum pressure during any given driving cycle. In fact, buffers which are much larger than expansion volumes will have much larger variations in pressure between $0 \%$ and $100 \%$ buffer. For the WLTP3 cycle, in dashed lines in Fig. 6 , the electrical power output does not vary significantly for different expansion or buffer volume. This is easily explained because there is hardly any accumulation during the whole cycle. 


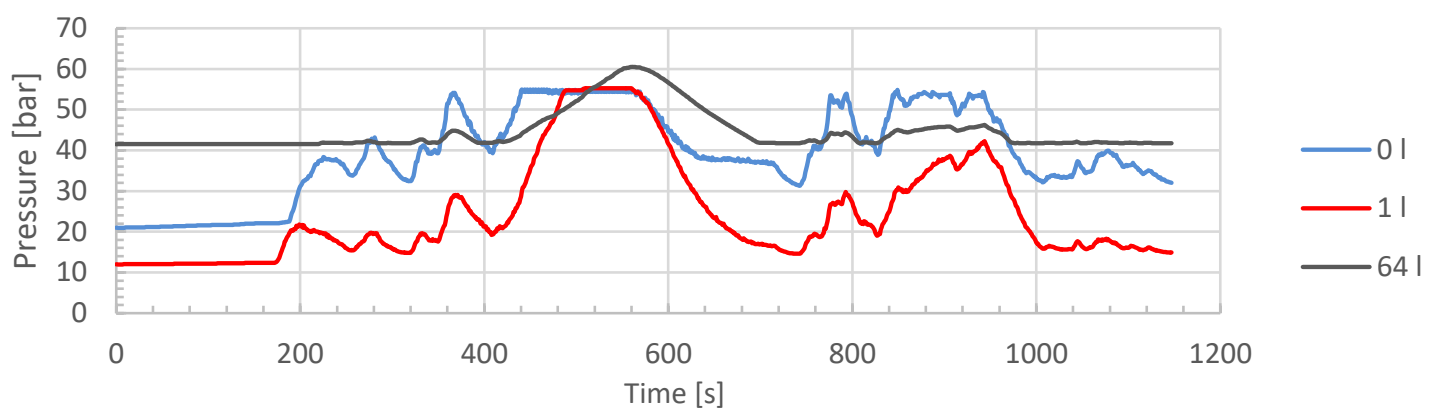

a)

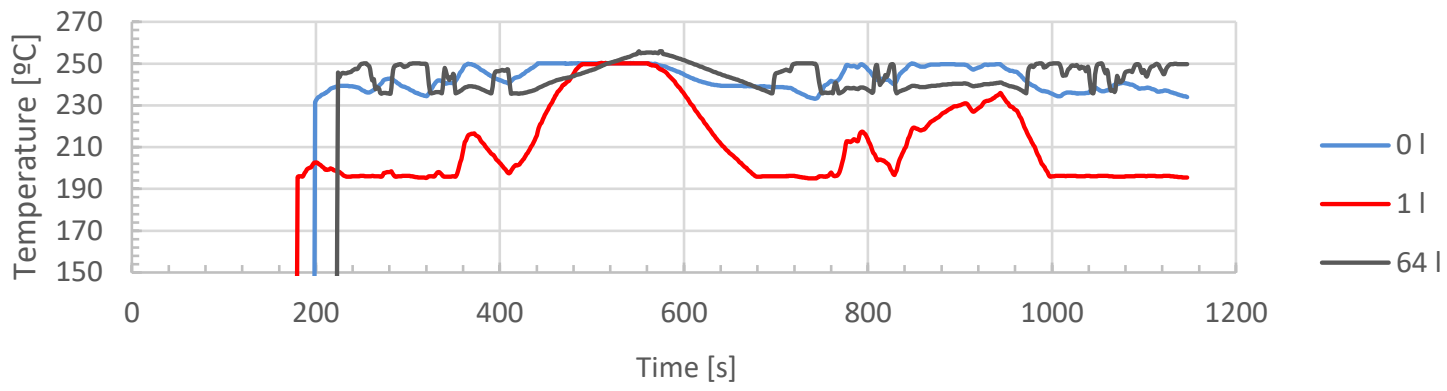

b)

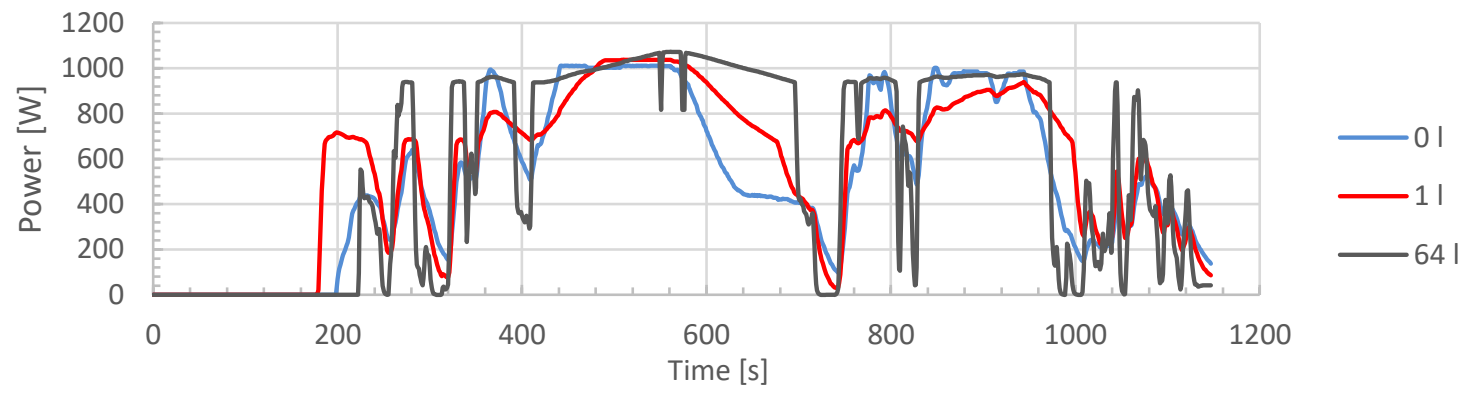

c)

Fig. 5 - variation of a) pressure b) hot face temperature c) electric power with time for different buffer volume in a custom highway cycle (expansion volume $0.5 \mathrm{l}$ )

Simulations were also performed for several buffer volumes with the same expansion volume and for several buffer volumes twice the expansion volume. It was observed that the electrical output is almost the same when the same volume proportion is applied between the two. Having the buffer twice the expansion volume provided slightly better results than identical buffer and expansion volumes.

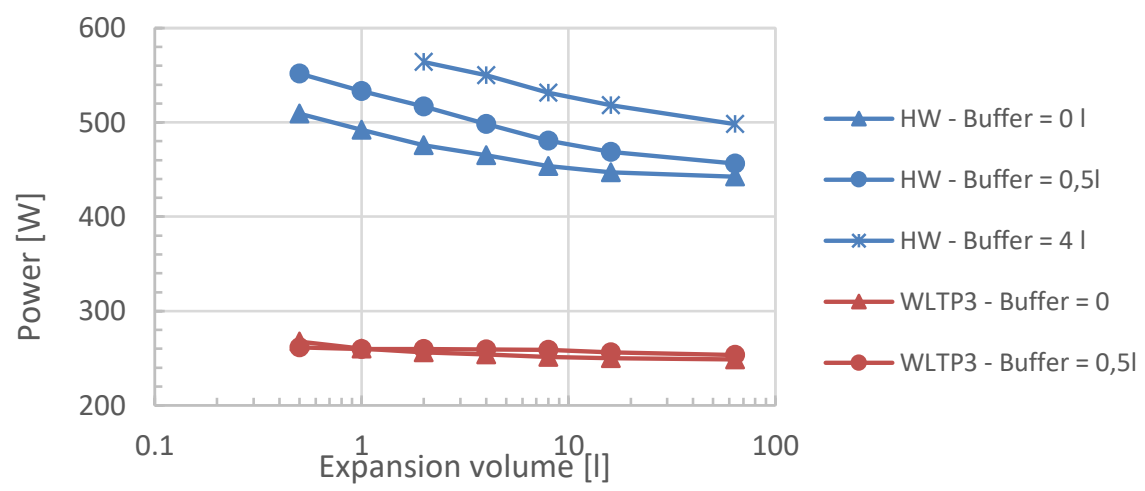

Fig. 6 - Average electrical power output for different expansion and buffer volumes for the WLTP3 and $H W$ cycle. 

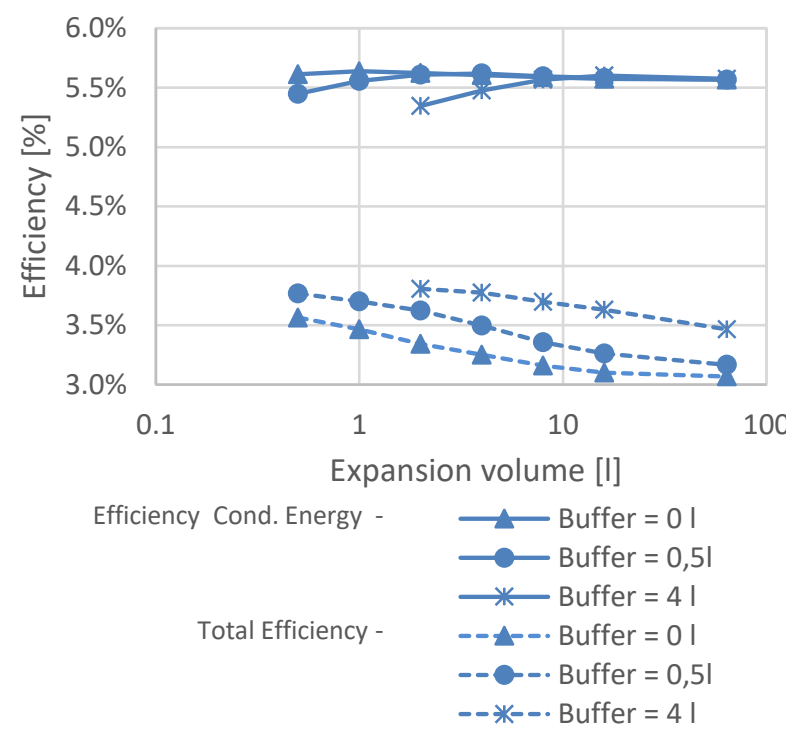

(a) the modules.
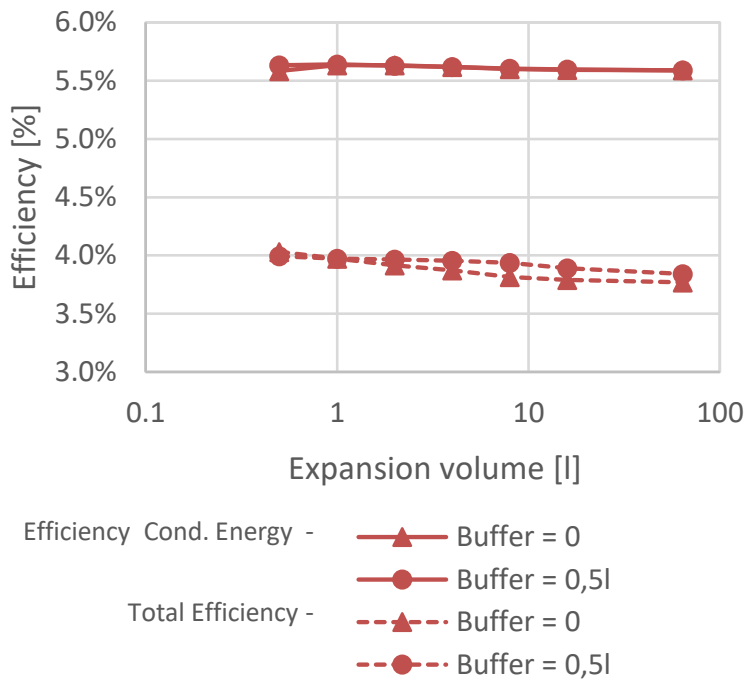

(b)

Fig. 7 shows the conversion efficiencies, for the HW and WLTP cycles, in relation to the total heat power available (dashed lines) and to the power that crosses the TEG modules. There we see that the buffer and expansion volume hardly influence the conversion efficiency based on the heat crossing

Fig. 7 - Conversion efficiency in relation to the total heat available (dashed lines) and in relation to the heat absorbed by the modules for different expansion and buffer volumes for (a) the custom highway cycle and b) the WLTP3 cycle.

Now, when considering overall conversion efficiency (based on total available thermal power) it can be seen that bigger buffers tend to provide a substantially better overall conversion efficiency in the case of the HW cycle than in the case of the WLTP cycle. This is so because in the HW cycle the buffer is more active than in the case of the WLTP cycle. A buffer with 11 and an expansion volume with 0.51 seems to be a good compromise between performance and system volume. That is why this configuration is chosen for the rest of the results.

\subsection{Influence of the initial pressure}

The initial, or pre-charge pressure chosen for the system will affect the maximum pressure achieved by the system and therefore the thermal level of the system. It is important to note that the lower the TS temperature, the lower will be the TEG temperature (which is bad for electric power) but also a higher fraction of the exhaust heat may be absorbed because the TS is at a lower temperature. In previous theoretical and experimental works by the authors, the optimum TS temperature was found to be dependent on the available exhaust heat [34,39]. The higher the available exhaust heat, the higher will be the optimum temperature of the TS system.

In Fig. 8 the electrical output and maximum temperature achieved at the TEG modules are plotted against the initial pressure (for standard conditions of a buffer/expansion volume of $11 / 0.51$ ). It may be seen that, for initial pressures above $1.2 \mathrm{MPa}$, the maximum allowed temperature in the custom highway cycle is exceeded, but the temperature achieved in the WLTP will only be excessive for initial pressures above $3.5 \mathrm{MPa}$. 

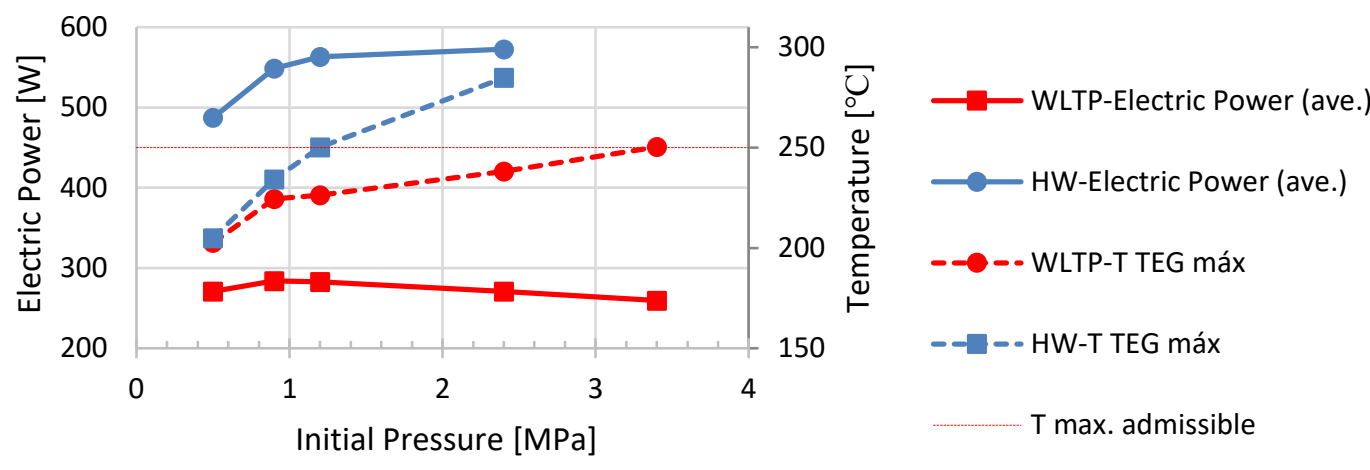

Fig. 8 - Electrical power and maximum TEG module temperature as a function of initial pressure (buffer volume $1 \mathrm{l}$, expansion volume $0.5 \mathrm{l}$ ).

Note that the maximum initial pressure allowed for the highway cycle nearly coincides with the optimum point of electricity production for the WLTP3 cycle, which is around 1.5 MPa and not the $3 \mathrm{MPa}$ that would result in a higher temperature. So, it seems that an initial pressure around $1.2 \mathrm{MPa}$ would roughly provide an optimum for the two driving cycles. This illustrates that when the available heat is not significant (like in the case of the WLTP3), it is better to work with lower pressure/temperature and absorb a higher fraction of the exhaust heat (larger active module area) than with a higher pressure, absorbing a lower fraction thereof.

Fig. 9 illustrates the variation of the active condenser and buffer length along the WLTP3 cycle for three different initial pressures $(0.5,1.2$ and $3.4 \mathrm{MPa})$. This cycle displays an initial light urban driving pattern, followed by a country road and finally a highway pattern. The higher the pressure, the higher will be the boiling temperature. The lowest initial pressure of $0.5 \mathrm{MPa}$ allows for an earlier start of electrical production in the cycle, because the boiling temperature is lower. Also, more modules are active for a longer period (active condenser length is higher) but at a lower temperature. This illustrates the fact that while higher temperatures will yield higher powers per active module, the number of active modules will typically be less with higher temperatures. Actually, the higher the TS temperature, the lower will be the power absorbed from the exhaust since in the limit the exhaust will only cool down to the TS temperature.

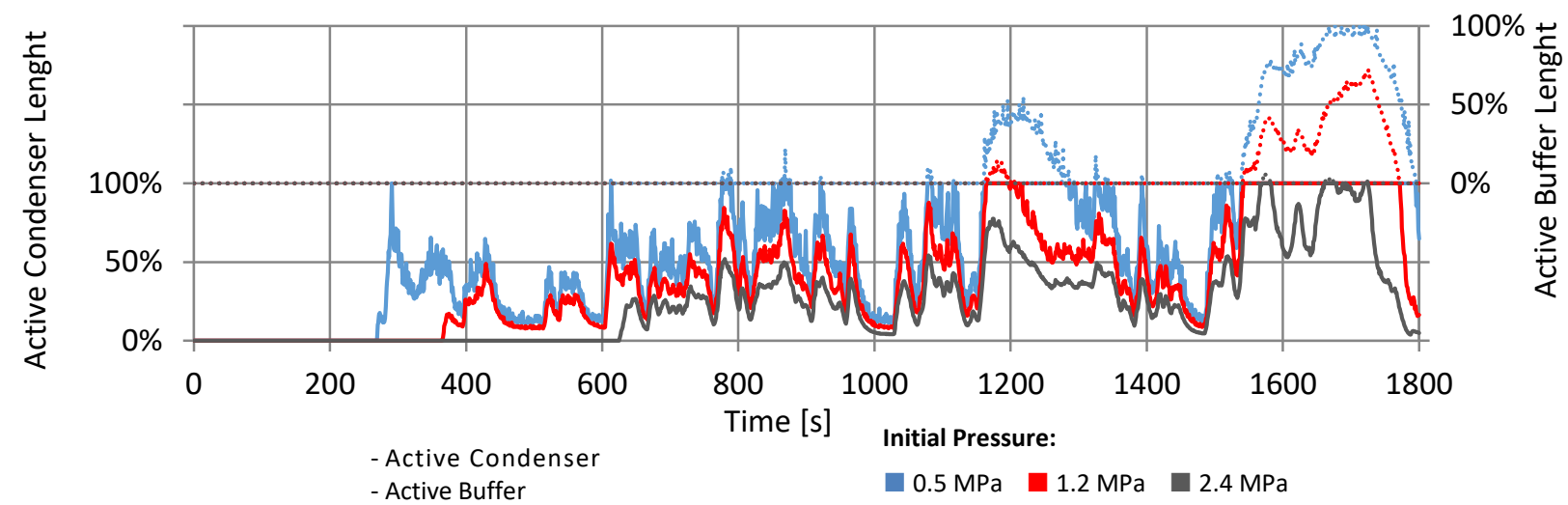

Fig. 9 - Influence of initial pressure on active condenser/buffer lengths in WLTP driving cycle (buffer volume $1 \mathrm{l}$, expansion volume $0.5 \mathrm{l}$ ).

Fig. 10 displays the electric output and TEG hot face temperature along the WLTP3 cycle. it may be seen that a lower initial pressure provides an earlier vapour production but also yields a lower stabilized TEG temperature. 


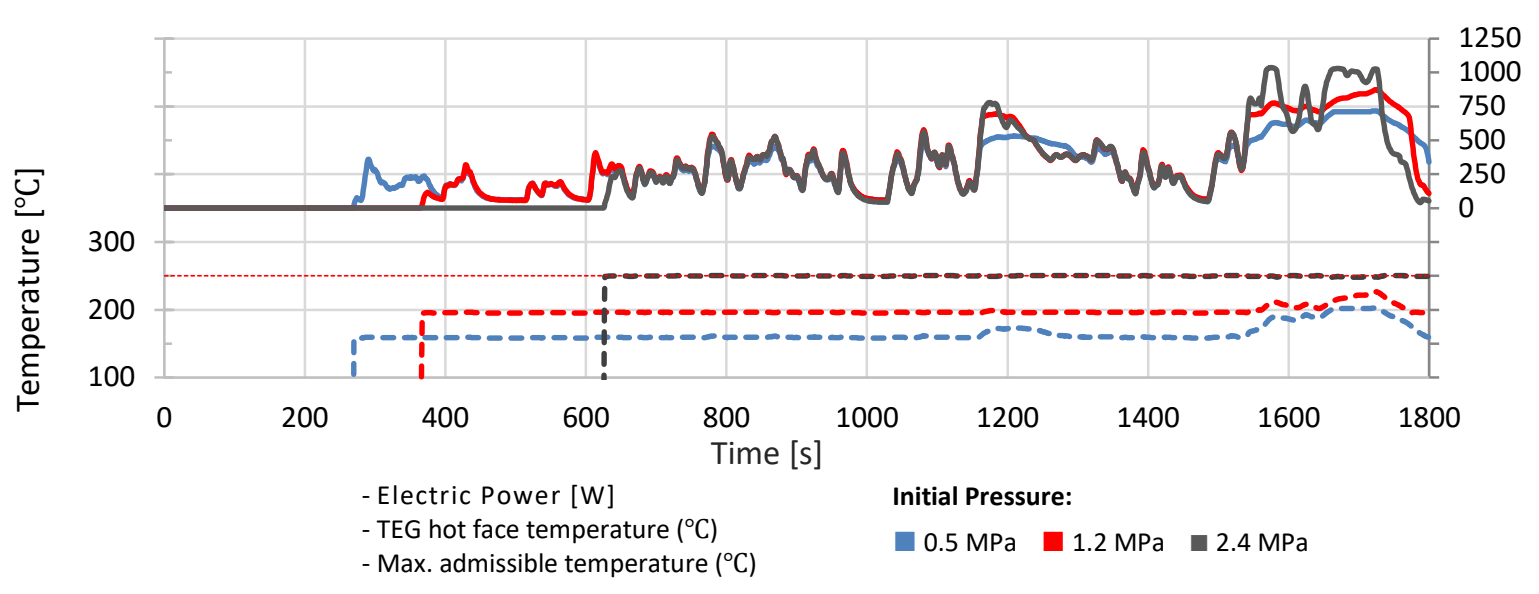

Fig. 10 - Influence of initial pressure on temperature and electrical power along the WLTP driving cycle (buffer volume $1 \mathrm{l}$, expansion volume $0.5 \mathrm{l}$ ).

Fig. 11, is similar to Fig. 9 but now for the HW cycle. This cycle has a much higher available thermal exhaust power in relation to the WLTP3 driving cycle as it includes an up-hill highway driving starting around $400 \mathrm{~s}$. For being a higher duty driving cycle, the vapour is generated and electrical power is produced much earlier than in the WLTP3 driving cycle. For this same reason, the buffer is more filled than in the case of the WLTP3 case, allowing for excess vapour storage during high power events.

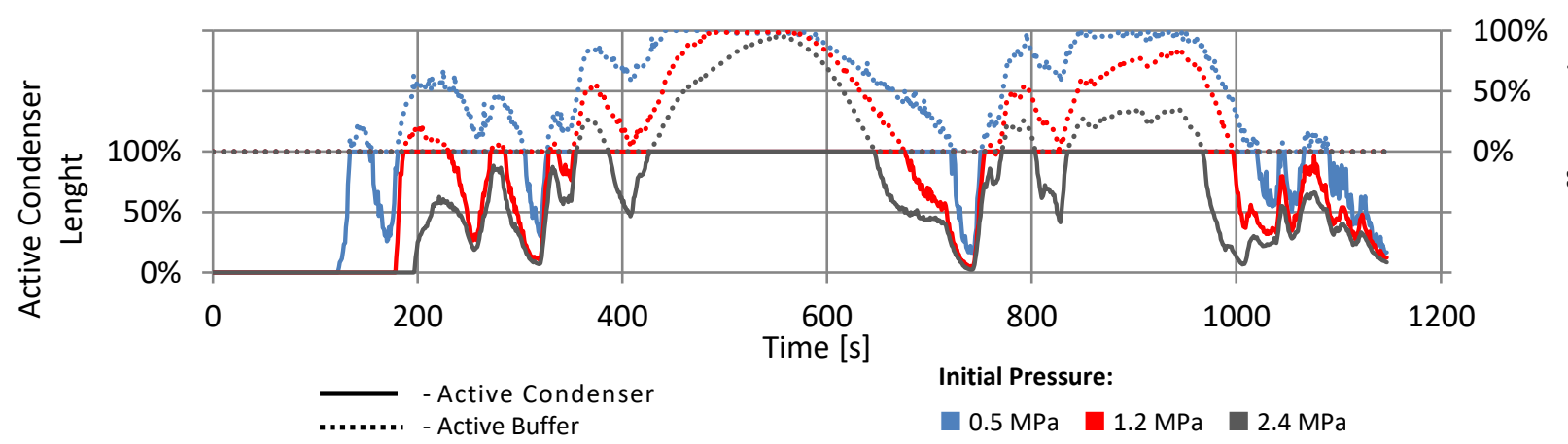

Fig. 11 - Influence of initial pressure on active condenser/buffer lengths percentage in $H W$ driving cycle (buffer volume $1 \mathrm{l}$, expansion volume $0.5 \mathrm{l}$ ).

Fig. 12 is similar to Fig. 10, but now power and TEG hot face temperature refer to the HW cycle. It shows that the average electrical power production is significantly higher as the initial pressure increases. For the initial pressure of $2.4 \mathrm{MPa}$ there are some points in the cycle where the maximum allowed temperature (in the present case, $250^{\circ} \mathrm{C}$ ) is exceeded, which is not acceptable. Hence, the initial pressure of 1.2 $\mathrm{MPa}$ would be the optimal solution here. 


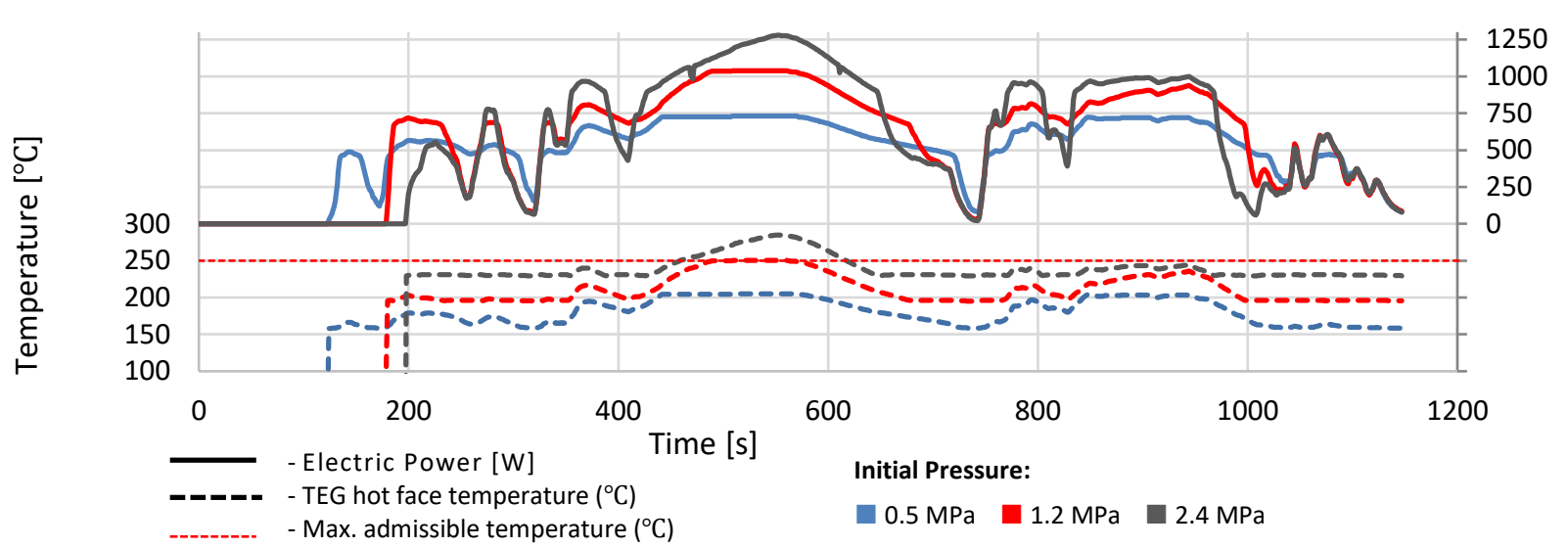

566

567

568

569

Fig. 12 - Influence of initial pressure on temperature and electrical power along the $H W$ driving cycle (buffer volume $1 \mathrm{l}$, expansion volume $0.5 \mathrm{l}$ ).

\subsection{Comparison with state-of-the-art}

A summary of the average and maximum powers obtained under both driving cycles for a fairly optimized system (1/0.5 litre of buffer/expansion volume, $1.2 \mathrm{MPa}$ of initial pressure) is summarized in Fig. 13. It is worth noting that both the average powers $(563 \mathrm{~W} / 283 \mathrm{~W}$ for the HW/WLTP3 cycles, respectively), and he maximum powers $(1.0 \mathrm{~kW}$ and $0.87 \mathrm{~kW}$, respectively) seem to be highly promising for such a light duty vehicle. It is worth noting that basically what the system does is to allow for a substantial absorption of the exhaust heat without the risk of overheating or thermal dilution. Evidence for this is the fact that the net conversion efficiency around $4 \%$ for both cycles is only slightly lower than the average conversion efficiency, which is close to the maximum efficiency of the TEG modules used (a little above 5\%). This means that the system has been thermally optimized and that the efficiency is mainly limited by the efficiency of the modules used. Once higher efficiency modules are used, the system is likely to provide even better performance.

It is important to compare the performance of the present concept against results from literature. A comprehensive revision of automotive TEGs has been made by Shen et al. [3]. Regarding the highest performing prototypes reported in literature it is worth mentioning both Bass et al [40], Zhang et al. [41] and Liu et al. [42] which obtained around $1 \mathrm{~kW}$ but for heavy duty (e.g. truck or military) engines, while one of the most successful projects involving automotive companies so far yielded a power around 600W at design conditions with a BMW X6 [43].
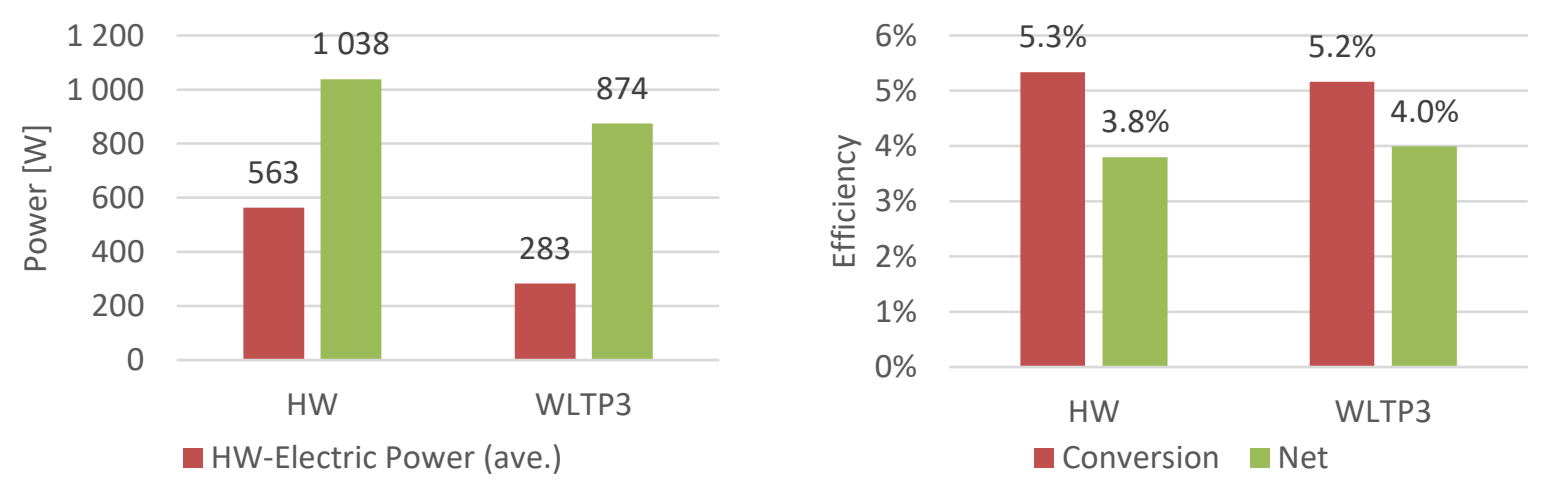

Fig. 13 - (a) Average and maximum Electric power produced by the system; (b) thermal to electric energy conversion efficiency and net TEG efficiency relatively to the available engine exhaust heat (buffer volume $1 \mathrm{l}$, expansion volume $0.5 \mathrm{l}$, initial pressure $1.2 \mathrm{MPa}$ ). 
The comparison with light duty engine studies seems even more advantageous, as well funded works such as those by the Oak Ridge National Laboratory recorded $300 \mathrm{~W}$ for high engine loads and around $50 \mathrm{~W}$ for normal driving scenarios [44]. It is also worth mentioning the work by Kim et al. [45] which used Constant Conductance HPs and achieved 350W. Naturally, it must be stated that these were real tests while the present analysis is still purely theoretical and has some simplifying assumptions. Nevertheless, the present analysis still yields quite positive results when compared with the 550W predicted by GM for a Chevrolet Suburban SUV [46] or the maximum powers of $188 \mathrm{~W} / 886 \mathrm{~W}$ predicted for a light/heavy duty vehicle by Vale et al. [47]. Regarding the average power produced, it seems that the results of the present study are unparalleled in literature [3]. It seems that the reason for this lies in the fact that it is possible to convert the thermal level of the exhaust down to the ideal operating temperature instead of designing the system for a target range and then wasting excess power events with a by-pass valve.

\subsection{Consumption and savings}

Taking as a standard the roughly optimized case of a system with a 1/0.5 l of buffer/expansion volume and an initial pressure of $1.2 \mathrm{MPa}$, the fuel consumption and $\mathrm{CO}_{2}$ emissions were calculated for three different cases: a conventional vehicle with alternator and mechanical peripherals (AC compressor, fuel pump, water pump); the same car with reduced alternator use (electrical needs partially produced from TEG system); the same car eliminating the alternator use (electrical needs produced entirely from waste energy systems); the same car eliminating the alternator use and switching the mechanical peripherals to electrically-driven ones (electrical needs produced from waste energy systems);

Table 3 shows the expected consumption and emissions savings for the HW and WLTP3 cycles based on the accessory consumptions presented previously in Table 1. It may be seen that when the TEG system is used, there is a fuel economy benefit of around $6 \%$ for both cycles under consideration. Please note that a $6 \%$ reduction in fuel will correspond to a $6 \%$ reduction in $\mathrm{CO}_{2}$ emissions. The electrical power produced in the highway cycle is sufficient to fully replace the alternator (as the average electrical needs are around 500W [23]). If all the peripheral components and alternator could be fully powered by the waste energy systems available in the car, then the savings in fuel could be as high as $12 \%$ for the highway and $24 \%$ for the WLTP3 cycle. The reason for the savings being so big in the case of the WLTP is that the relative weight of the peripherals in the total required mechanical power of the engine is very high. Also, the average efficiency of the engine is lower, so the elimination of the mechanical peripherals corresponds to a much higher fuel savings than in the case of the HW cycle.

Table 4 shows the yearly fuel savings computed by the model for different user profiles. It spans from the EU user profiles with lower/higher average vehicle usage $(15 \mathrm{k}$ and $30 \mathrm{k} \mathrm{km} /$ year for UK/Poland, respectively [48]), to users with an intensive (60k km/year) or even extra-intensive use (120k $\mathrm{km} /$ year).

Calculations were also performed for combinations of the HW and WLTP3 cycles in different orders. The fuel savings that the system can deliver are interesting, from 851 for an annual use of $15000 \mathrm{~km}$ in a highway cycle, to 8831 for the extra intensive use of $120000 \mathrm{~km}$ on the double WLTP3 cycle. The potential maximum fuel savings, when all the peripheral components are removed, can be as high as 32751 annually. 
Table 3 - Predicted consumption, emissions and savings for several energy recovery configurations

\begin{tabular}{lll}
\hline & HW & WLTP3 \\
\hline Distance [km] & 27.1 & 23.3 \\
Time [s] & 1147 & 1800 \\
Average engine efficiency [\%] & $25 \%$ & $18 \%$ \\
Average required Mechanical Power [kW] & 18.7 & 8.58 \\
\hline Using TEG system: & & \\
\hline Power Produced (ave.) [W] & 563 & 283 \\
Energy Produced [kJ/km] & 23.9 & 21.9 \\
Average required Mechanical Power [kW] & 17.6 & 8.1 \\
Fuel Saved [1 / 100km] & 0.57 & 0.68 \\
Fuel Saved [\%] & $6.0 \%$ & $6.0 \%$ \\
$\mathrm{CO}_{2}$ Emissions Savings [g/km] & 13.6 & 16.4 \\
\hline Removing alternator: & & \\
\hline Average Alternator Electric power [kW] & 0.5 & 0.5 \\
Alternator Mechanical Power [kW] & 1.00 & 0.91 \\
Average required Mechanical Power [kW] & 17.7 & 7.67 \\
Fuel Saved [1/ 100km] & 0.51 & 1.20 \\
Fuel Saved [\%] & $5.3 \%$ & $10.6 \%$ \\
$\mathrm{CO}_{2}$ Emissions Savings [g/km] & 12.1 & 28.8 \\
\hline Removing alternator and peripherals: & & \\
\hline Alternator and Peripheral Mechanical Power [kW] & 2.24 & 2.06 \\
Average required Mechanical Power [kW] & 16.5 & 6.51 \\
Fuel Saved [1/100km] & 1.13 & 2.73 \\
Fuel Saved [\%] & $12 \%$ & $24 \%$ \\
$\mathrm{CO}_{2}$ Emissions Savings [g/km] & 27.0 & 65.3 \\
\hline
\end{tabular}

Table 4-Calculated yearly fuel savings, in gasoline litres, for several user profiles

\begin{tabular}{llllll}
\hline km/year & HW & WLTP3 & HW-double & WLTP3-double & HW-WLTP3-HW \\
\hline Using TEG system & & & & & \\
\hline 15 k - minimum EU (UK) & 85.2 & 102 & 90.7 & 110 & 95.2 \\
30 k maximum EU (Poland) & 170 & 205 & 181 & 220 & 190 \\
60 k intensive use & 341 & 410 & 362 & 441 & 381 \\
120 k extra intensive use & 682 & 821 & 725 & 883 & 762 \\
\hline \multicolumn{2}{l}{ Removing alternator and peripherals } & & & & \\
\hline 15 k minimum EU (UK) & 169 & 409 & 169 & 409 & 233 \\
30 k maximum EU (Poland) & 338 & 818 & 338 & 819 & 466 \\
60 k intensive use & 677 & 163 & 677 & 1638 & 932 \\
120 k extra intensive use & 1354 & 3275 & 1355 & 3275 & 1865 \\
\hline
\end{tabular}

\section{Conclusions}

The present work assessed the efficiency gains of a vehicle incorporating a temperature-controlled exhaust heat thermoelectric generator (TEG) suitable for highly variable thermal input (e.g. driving cycle). This generator concept incorporates a variable conductance thermosiphon (TS) whose 
function is to act as a thermal interface, downgrading the temperature at which the exhaust energy is supplied to the thermoelectric modules to an optimized level, irrespective of thermal load.

The main novelty of the present work was the detailed thermal modelling of the variable conductance TS, including the computation of the evolution of the inner pressure and temperature of the system (in previous publications, pressure and boiling temperature was considered fixed), based on the computation of masses and volumes occupied by the fluids, as well as the corresponding electric power output provided by the TEGs during two different driving cycles.

An assessment of the influence of the expansion and buffer volumes, and pre-charge pressure of the system on its performance and a study of the annual energy/fuel and $\mathrm{CO}_{2}$ emissions savings obtained with the implementation of the system for typical European usage were made.

The following findings were made:

- It was possible to model realistically the heat transfer and the pressure/temperature variation from the exhaust of the car to the TEG generator via the TS along highly variable driving cycles. The results indicate that indeed it is possible to maintain the TEG temperature within a controlled temperature range avoiding both thermal dilution and overheating. To the best of the authors' knowledge, the temperature control feature proposed by the authors is unique in TEG systems.

- Although bigger expansion and buffer volumes provided higher thermal stability for the system, smaller volumes maximized the electrical output. Allowing for some mild pressure/temperature variation seems advantageous for this purpose.

- Average generated electric powers of 563W and $283 \mathrm{~W}$ were predicted for a custom highway (HW) and the WLTP class 3 driving cycles, which seem to be state-of-the-art results for such light duty vehicles. Considering energy production per $\mathrm{km}$, the results were much closer ( 24 and $22 \mathrm{~kJ} / \mathrm{km}$, respectively). The reason for these good results seems to be that the active TEG modules are always operating near top efficiency due to the thermal control achieved over the hot face temperature and because the system is able to downgrade the temperature of high power events instead of wasting them using a by-pass valve.

- Considering the reductions in alternator use, the fuel and $\mathrm{CO}_{2}$ emissions savings obtained with using the TEG system were around 6\%. If the alternator could be eliminated altogether and the air conditioning system and water/oil pumps turned into electrical components driven exclusively by waste energy recovery systems (including regenerative braking), the fuel and $\mathrm{CO}_{2}$ emissions savings could be as high as $12 \%$ and $24 \%$ for the HW and WLTP driving cycles, respectively.

- Annual savings in gasoline for using the TEG system could be as high as 102, 205, 410 and 8211 / year considering EU users with lowest average vehicle usage (UK), highest average vehicle usage (Poland), intensive users $(60 \mathrm{k} \mathrm{km} / \mathrm{year})$ and extra-intensive users $(120 \mathrm{k}$ $\mathrm{km} / \mathrm{year}$ ). These figures would jump to 409, 818, 163 and 32751 / year in the case where peripherals are driven exclusively by waste energy recovery systems.

The concept herein analysed seems to have very good potential for vehicle waste energy recovery applications, especially in situations where available space is not so critical (e.g. heavy duty applications). Therefore, it is paramount that extensive theoretical and experimental research be carried out to explore this potential and eliminate its limitations in volume, cost and form factor.

\section{Acknowledgments}

This work had the support of Fundação para a Ciência e Tecnologia, Project Exhaust2Energy (PTDC/EMS-ENE/3009/2014), MEtRICs - Mechanical Engineering and Resource Sustainability Centre (UID/EMS/04077/2019), sabbatical grant (J. Martins) SFRH/BSAB/142994/2018, Postdoctoral grant (F.P. Brito) SFRH/BPD/89553/2012 and M-ERA.NET Project THERMOSS, financed by FEDER funds through P.O. F.C. - COMPETE and National funds through PIDDAC. 
Nomenclature

\begin{tabular}{|c|c|c|c|}
\hline Acronyms & & $p$ & iteration $\mathrm{p}$, in time \\
\hline $\mathrm{AC}$ & Air Conditioning & $u$ & iteration $\mathrm{u}$, in pressure \\
\hline HW & Custom Highway driving cycle & convergen & algorithm \\
\hline GHG & greenhouse-gas & vapour & vapour (property of) \\
\hline $\mathrm{HE}$ & heat exchanger & water & water (property of) \\
\hline ICE & internal combustion engine & Variables & \\
\hline OEM & $\begin{array}{l}\text { Original Equipment } \\
\text { Manufacturer }\end{array}$ & $c_{p}$ & $\begin{array}{l}\text { specific heat at constant pressure } \\
\mathrm{J} /(\mathrm{kg} \mathrm{K})\end{array}$ \\
\hline ORC & Organic Rankine Cycle & $E$ & thermal energy, $\mathrm{J}$ \\
\hline TE & Thermoelectric & $E_{\text {cond }}$ & condensation energy, $\mathrm{J}$ \\
\hline TEG & Thermoelectric generator & $E_{\text {evap }}$ & $\begin{array}{l}\text { condensation energy, J } \\
\text { evaporator energy, } \mathbf{J}\end{array}$ \\
\hline VCTS & $\begin{array}{l}\text { Variable Conductance } \\
\text { Thermosiphon }\end{array}$ & $E_{\text {to boiling }}$ & $\begin{array}{l}\text { Energy required to reach } \\
\text { boiling/saturation conditions }\end{array}$ \\
\hline WLTP3 & $\begin{array}{l}\text { Worldwide harmonized Light } \\
\text { vehicles Test Procedure class } 3 \\
\text { driving cycle }\end{array}$ & $E_{\text {wall in }}$ & $\begin{array}{l}\text { Energy reaching the evaporator } \\
\text { interior and coming from the } \\
\text { exhaust flow }\end{array}$ \\
\hline Greek sym & ols & $L$ & length, $\mathrm{m}$ \\
\hline$\Delta \mathrm{t}$ & time step & $m$ & mass, $\mathrm{kg}$ \\
\hline$\Delta h_{L V}$ & latent heat of vaporization, $\mathrm{J} / \mathrm{kg}$ & $P_{e}$ & electric power, W \\
\hline$\rho$ & density, $\mathrm{kg} / \mathrm{m}^{3}$ & $T$ & temperature, ${ }^{\circ} \mathrm{C}$ \\
\hline Subscripts & d superscripts & $T_{T S}$ & Thermosiphon temperature \\
\hline metal & $\begin{array}{l}\text { equivalent metal (mass) to } \\
\text { account for thermal inertia }\end{array}$ & $V^{\prime}$ & volume, $\mathrm{m}^{3}$ \\
\hline
\end{tabular}

\section{References}

[1] Dominković DF, Bačeković I, Pedersen AS, Krajačić G. The future of transportation in sustainable energy systems: Opportunities and barriers in a clean energy transition. Renew Sustain Energy Rev 2018;82:1823-38. doi:10.1016/J.RSER.2017.06.117.

[2] Champier D. Thermoelectric generators: A review of applications. Energy Convers Manag 2017;140:167-81. doi:10.1016/J.ENCONMAN.2017.02.070.

[3] Shen ZG, Tian LL, Liu X. Automotive exhaust thermoelectric generators: Current status, challenges and future prospects. Energy Convers Manag 2019;195:1138-73. doi:10.1016/j.enconman.2019.05.087.

[4] TransportPolicy.net. EU: LIGHT-DUTY: GHG EMISSIONS n.d.

[5] Martins J, Brito FP. Carros Elétricos. Porto: Publindústria; 2012.

[6] Burch I, Gilchrist J. Survey of Global Activity to Phase Out Internal Combustion Engine Vehicles 2018:14.

[7] Alagumalai A. Internal combustion engines: Progress and prospects. Renew Sustain Energy Rev 2014;38:561-71. doi:10.1016/J.RSER.2014.06.014.

[8] Martins J. Motores de Combustão Interna. vol. 53. 4ª edição. Porto: Publindústria; 2006.

[9] Van Basshuysen R, Schaefer F. Internal Combustion Engine Handbook. 2nd Englis. Warrendale: SAE International; 2016.

[10] Ribeiro B, Martins J. Direct Comparison of an Engine Working under Otto, Miller and Diesel 
Cycles: Thermodynamic Analysis and Real Engine Performance 2007. doi:10.4271/2007-010261.

[11] Martins J, Brito F. Carros Eletricos. PUBLINDUSTRIA; 2012.

[12] Ribau J, Silva C, Brito FP, Martins J. Analysis of four-stroke, Wankel, and microturbine based range extenders for electric vehicles. Energy Convers Manag 2012;58:120-33. doi:10.1016/j.enconman.2012.01.011.

[13] Gabriel-Buenaventura A, Azzopardi B. Energy recovery systems for retrofitting in internal combustion engine vehicles: A review of techniques. Renew Sustain Energy Rev 2015;41:955-64. doi:10.1016/J.RSER.2014.08.083.

[14] Peng Z, Wang T, He Y, Yang X, Lu L. Analysis of environmental and economic benefits of integrated Exhaust Energy Recovery (EER) for vehicles. Appl Energy 2013;105:238-43. doi:10.1016/j.apenergy.2013.01.004.

[15] Ji D, Wei Z, Mazzoni S, Mengarelli M, Rajoo S, Zhao J, et al. Thermoelectric generation for waste heat recovery: Application of a system level design optimization approach via Taguchi method. Energy Convers Manag 2018;172:507-16. doi:10.1016/J.ENCONMAN.2018.06.016.

[16] Wang T, Zhang Y, Peng Z, Shu G. A review of researchs on thermal exhaust heat recovery with Rankine cycle. Renew Sustain Energy Rev 2011;15.

[17] Patowary R, Baruah D. Thermoelectric conversion of waste heat from IC engine-driven vehicles: A review of its application, issues, and solutions. 2018. doi:10.1002/er.4021.

[18] Rowe DM. CRC Handbook of Thermoelectrics. 1995. doi:10.1201/9781420049718.

[19] LaGrandeur J, Crane D, Hung S, Mazar B, Eder A. Automotive Waste Heat Conversion to Electric Power using Skutterudite, TAGS, PbTe and BiTe. 2006 25th Int. Conf. Thermoelectr., IEEE; 2006, p. 343-8. doi:10.1109/ICT.2006.331220.

[20] Zervos H. Waste heat recovery systems in vehicles. Energy Harvest J 2011. doi:http://www.energyharvestingjournal.com/articles/waste-heat-recovery-systems-invehicles-00003754.asp.

[21] Meisner GP. Skutterudite Thermoelectric Generator For Automotive Waste Heat Recovery. 3rd Thermoelectr Appl Work 2012.

[22] Mori M, Yamagami T, Sorazawa M, Miyabe T, Takahashi S, Haraguchi T. Simulation of Fuel Economy Effectiveness of Exhaust Heat Recovery System Using Thermoelectric Generator in a Series Hybrid. SAE Int J Mater Manuf 2011;4:1268-76. doi:10.4271/2011-01-1335.

[23] Carlson B. On-road Data Collection and Analysis: 12 Volt Auxiliary Load, Energy Storage \& Transportation Systems 2015.

[24] A Zulkifli A, Dahlan A, H Zulkifli A, Nasution H, abdul aziz A, Mohd Perang MR, et al. Impact of the electric compressor for automotive air conditioning system on fuel consumption and performance analysis. vol. 100. 2015. doi:10.1088/1757-899X/100/1/012028.

[25] Bradfield M. Improving Alternator Efficiency Measurably Reduces Fuel Costs 2008.

[26] Wang X, Liang X, Hao Z, Chen R. Comparison of electrical and mechanical water pump performance in internal combustion engine. 2015. doi:10.13140/RG.2.1.4751.8886.

[27] Meyer R, Braun H, Rehage R, Weinmann H. Alternators and Starter Motors 2003.

[28] Meira J, Filho A, Melo W, Ribeiro E. Strategies for Energy Savings with Use of Constant and Variable Oil Pump Systems. 2011. doi:10.4271/2011-36-0150.

[29] Araiz M, Martínez A, Astrain D, Aranguren P. Experimental and computational study on thermoelectric generators using thermosyphons with phase change as heat exchangers. Energy Convers Manag 2017;137. doi:10.1016/j.enconman.2017.01.046.

[30] Holman JP. Heat Transfer. 1986.

[31] Orr B, Akbarzadeh A, Mochizuki M, Singh R. A review of car waste heat recovery systems 
utilising thermoelectric generators and heat pipes. Appl Therm Eng 2016;101:490-5.

[32] Reay D, Kew P, Mcglen R. Heat Pipes: Theory, Design and Applications: Sixth Edition. 2013.

[33] Brito FP, Martins J, Goncalves LM, Sousa R. Temperature Controlled Exhaust Heat Thermoelectric Generation. SAE Int J Passeng Cars - Electron Electr Syst 2012;5. doi:10.4271/2012-01-1214.

[34] Brito FP, Martins J, Hançer E, Antunes N, Gonçalves LM. Thermoelectric Exhaust Heat Recovery with Heat Pipe-Based Thermal Control. J Electron Mater 2015;44:1984-97. doi:10.1007/s11664-015-3638-3.

[35] Brito FP, Alves A, Pires JM, Martins LB, Martins J, Oliveira J, et al. Analysis of a Temperature-Controlled Exhaust Thermoelectric Generator During a Driving Cycle. J Electron Mater 2016;45:1846-70. doi:10.1007/s11664-015-4258-7.

[36] Martins JJG, Uzuneanu K, Ribeiro BS, Jasasky O. Thermodynamic Analysis of an OverExpanded Engine, 2004. doi:10.4271/2004-01-0617.

[37] Martins LASB, Araujo BJO, Martins JJG, Brito FCP. Methodology for the Energy Characterization of Type-Approval and Real-World Driving Cycles for Passenger Vehicles. ASME Int. Mech. Eng. Congr. Expo. Proc., vol. 6A-2015, 2015, p. V06AT07A040. doi:10.1115/IMECE2015-53669.

[38] Brito FP, Figueiredo L, Rocha LA, Cruz AP, Goncalves LM, Martins J, et al. Analysis of the Effect of Module Thickness Reduction on Thermoelectric Generator Output. J Electron Mater 2016;45:1711-29. doi:10.1007/s11664-015-4182-x.

[39] Brito FP, Goncalves LM, Martins J, Antunes N, Sousa D. Influence of heat pipe operating temperature on exhaust heat thermoelectric generation. SAE Int J Passeng Cars - Mech Syst 2013;6. doi:10.4271/2013-01-0559.

[40] Bass JC, Elsner N, Leavitt F. Performance of the $1 \mathrm{~kW}$ thermoelectric generator for diesel engines. AIP Conf Proc 1995;316:295-295. doi:doi:10.1063/1.46818.

[41] Zhang Y, Cleary M, Wang X, Kempf N, Schoensee L, Yang J, et al. High-temperature and high-power-density nanostructured thermoelectric generator for automotive waste heat recovery. Energy Convers Manag 2015;105. doi:10.1016/j.enconman.2015.08.051.

[42] Liu X, Deng YDD, Li Z, Su CQQ. Performance analysis of a waste heat recovery thermoelectric generation system for automotive application. Energy Convers Manag 2015;90:121-7.

[43] Crane D, LaGrandeur J, Jovovic V, Ranalli M, Adldinger M, Poliquin E, et al. TEG OnVehicle Performance and Model Validation and What It Means for Further TEG Development. J Electron Mater 2013;42:1582-91. doi:10.1007/s11664-012-2327-8.

[44] Szybist J, Davis S, Thomas J, Kaul B. Performance of a Half-Heusler Thermoelectric Generator for Automotive Application 2018.

[45] Kim S-K, Won B-C, Rhi S-H, Kim S-H, Yoo J-H, Jang J-C. Thermoelectric Power Generation System for Future Hybrid Vehicles Using Hot Exhaust Gas. J Electron Mater 2011;40:77883. doi:10.1007/s11664-011-1569-1.

[46] Kumar S, Heister SD, Xu X, Salvador JR, Meisner GP. Thermoelectric generators for automotive waste heat recovery systems part I: Numerical modeling and baseline model analysis. J Electron Mater 2013;42:665-74. doi:10.1007/s11664-013-2471-9.

[47] Vale S, Heber L, Coelho PJ, Silva CM. Parametric study of a thermoelectric generator system for exhaust gas energy recovery in diesel road freight transportation. Energy Convers Manag 2017;133:167-77. doi:10.1016/J.ENCONMAN.2016.11.064.

[48] Guzay PK, Davide F, Angelo M, Gabriella S, Andrea A, Alyona Z, et al. Driving and parking patterns of European car drivers - a mobility survey. 2012. doi:10.2790/70746. 